\title{
Geographic Distribution of Incompatibility Alleles in Cultivars and Selections of European Hazelnut
}

\author{
Shawn A. Mehlenbacher ${ }^{1}$ \\ 4017 Ag \& Life Sciences Building, Department of Horticulture, Oregon State University, Corvallis, \\ OR 97331
}

\begin{abstract}
AdDitional INDEX wORDs. Corylus avellana, filbert, nut breeding, pollenizer, sporophytic
Abstract. The european hazelnut (Corylus avellana L.) is native to most of Europe and nearby areas in Asia Minor and the Caucasus Mountains. Cross-pollination is enforced by sporophytic incompatibility under the control of a single locus with multiple alleles (haplotypes). Fluorescence microscopy is routinely used to determine if a pollination is compatible or incompatible, and use of an array of known testers allows identification of the alleles of cultivars and selections. Both alleles are expressed in the stigmas, but often only one is expressed in the pollen because of dominance. Cultivars are highly heterozygous diploids $(2 n=2 x=22)$ and clonally propagated. Most of the world's leading cultivars were selected from local wild populations near where they are now planted on a commercial scale. Genetic improvement efforts are recent and, although tremendous genetic variability is available, such efforts have had little impact outside of Oregon and France. Studies of genetic diversity using simple sequence repeat markers have placed most cultivars in one of the four main groups: Spanish-Italian, Central European, English, or Black Sea. This study presents 17 years of data on incompatibility in hazelnut, including the discovery of six new S-alleles and determination of the dominance relationships among $105 \mathrm{new}$ pairs of alleles. The total number of alleles now stands at 33 . The S-alleles of 284 cultivars, 13 interspecific hybrids, and 522 selections of diverse origin are presented. The $S$-alleles identified in hazelnut cultivars is information that should be useful to breeders in the planning of crosses, to curators of germplasm collections, and to growers and nurseries as they choose cultivars and pollenizers when designing orchards. Differences in S-allele frequency seen in the cultivars and selections are related to geographic origin. The most common alleles of cultivars in the major geographical groups are $S_{2}$ in the Spanish-Italian group, $S_{5}$ in the Central European group, $S_{3}$ in the English group, and $S_{4}$ in the Black Sea group. Most selections belonged to the Black Sea group, and $S_{4}$ was by far the most common allele. Differences in allele frequency were also observed among seed lots within a country.
\end{abstract}

European hazelnut, a member of the Betulaceae, is monoecious, dichogamous, and wind-pollinated. Hazelnuts thrive in maritime climates where temperatures are moderate in winter and summer. The major world producers of hazelnuts are Turkey and Italy with additional production in Azerbaijan, the United States, Georgia, Spain, Iran, China, and France (Food and Agriculture Organization of the United Nations, 2011). Hazelnuts were cultivated in the Roman Empire and much earlier near the Black Sea in Turkey and the Caucasus. Most of the world's production is based on selections from local wild populations with different cultivars grown in each zone. Most cultivars are single clones, although some, including a few leading Turkish types (e.g., Tombul), appear to be groups of clones with similar phenotypes. Cultivars are traditionally propagated from suckers or by layerage, although grafting and in vitro culture are also possible. The local origin of important cultivars, and their limited movement from one production zone to another, contrasts sharply with the situation with the major food crops.

Pollen-stigma incompatibility in hazelnut is of the sporophytic type and controlled by a single locus, designated the

Received for publication 29 Oct. 2013. Accepted for publication 31 Dec. 2013. The Oregon State University hazelnut breeding program is supported by State, Hatch Act and Oregon Hazelnut Commission funds. Additional support was provided by a specific cooperative agreement with the U.S. Department of Agriculture.

A technical paper of the Oregon Agricultural Experiment Station.

Funding from the Oregon Hazelnut Commission, State of Oregon, and Hatch

Act is acknowledged and appreciated.

${ }^{1}$ Corresponding author. E-mail: mehlenbs@hort.oregonstate.edu.
S-locus, with multiple alleles (haplotypes), and the stigmatic surface is the site of the incompatibility reaction (Thompson, 1979a). Thompson (1979b) listed the alleles of several cultivars. Additional early work on S-allele identification was reviewed by Germain (1994). Hampson et al. (1993) used electron microscopy to study compatible and incompatible pollinations in detail. Hazelnuts are diploid $(2 n=2 x=22)$, and most cultivars are heterozygous at the S-locus. Fluorescence microscopy is used routinely to determine if a pollination is compatible or incompatible and to identify the S-alleles in cultivars and selections (Mehlenbacher, 1997a). Mehlenbacher (1997b) reported 25 S-alleles and for each allele identified a tester genotype whose pollen expresses that allele. Mehlenbacher (1997b) updated the results of Mehlenbacher and Thompson (1988) and presented dominance relationships based on 233 pairs of alleles. In all pairs, both alleles were expressed in the stigmas, but often only one was expressed by the pollen because of dominance. The dominance hierarchy is linear with eight levels (Mehlenbacher, 1997b). By convention, the allele(s) expressed in the pollen are underlined. Recently, Martins et al. (2012) investigated the S-alleles of Portuguese landraces, and Mehlenbacher (2013) listed the S-alleles of 282 cultivars. The linkage map of Mehlenbacher et al. (2006), constructed using random amplified polymorphic DNA and simple sequence repeat (SSR) markers, placed the S-locus on linkage group 5 (LG5).

Self-pollination of most cultivars results in very low nut set. Mehlenbacher and Smith (1991) identified partial selfcompatibility in 'Montebello', 'Tombul', and a few offspring of 'Montebello'. In this material, self-pollination unfortunately 
resulted in low nut set and a high frequency of blanks. More recently, Mehlenbacher and Smith (2006) identified selfcompatible seedlings of the cutleaf hazelnut [Corylus avellana f. heterophylla (Loud.) Rehder]. In these seedlings, self-pollination results in good nut set and few blanks. The cutleaf hazelnut has alleles $\mathrm{S}_{20}$ and $\mathrm{S}_{28}$. The latter gives self-compatibility when combined with a second allele low in the dominance hierarchy.

In this study, I identified six new S-alleles and determined the dominance relationships for 105 new pairs of alleles. I determined the alleles of 522 selections originating from nuts imported from many locations and examined the data for cultivars and selections for geographic patterns in the distribution of S-alleles.

\section{Materials and Methods}

The hazelnut breeding program at Oregon State University (OSU), in cooperation with the U.S. Department of Agriculture, Agriculture Research Service, National Clonal Germplasm Repository (USDA-ARS-NCGR) in Corvallis, OR, imported scions of cultivars from Georgia, Azerbaijan, and several European countries. The scions were grafted to rooted layers, held in post-entry quarantine for two growing seasons, and then planted in the field. When the trees began to flower, generally the fourth year after planting, incompatibility testing was performed as described by Mehlenbacher (1997a). Two to four branches on each tree were marked, emasculated by clipping the catkins, and enclosed in two bags: an inner bag of Tyvek housewrap (DuPont, Wilmington, DE) and an outer bag of a cotton-polyester blend (Smith and Mehlenbacher, 1994). Pollen was collected from tester trees (Table 1) and stored in the freezer at $-18^{\circ} \mathrm{C}$. From mid-January to early March, when styles had emerged and were receptive, females were collected from bagged branches using forceps and brought to the laboratory in petri dishes. Pollinations were performed in the laboratory the afternoon after collection by holding the female with forceps, dipping the styles into the vial of pollen, tapping the flower on the side of the vial to remove excess pollen, and placing the pollinated flower on a double layer of moist P5 filter paper (Fisher Scientific, Pittsburgh, PA). Unpollinated flowers were held in the refrigerator for a few days in petri dishes over moist filter paper to allow repetition of the pollinations if the first results were unclear. The day after pollination, styles were detached from the buds, squashed in aniline blue dye, and examined at $100 \times$ with a fluorescence microscope under ultraviolet light. Each pollination was scored as compatible or incompatible. In compatible pollinations, pollen germination was excellent and tubes could be seen growing parallel down the style. In incompatible pollinations, germination was often reduced, pollen tubes were short and did not penetrate the stigmatic surface, and the tubes often ended in bulbs. In most cases, the use of fresh, unpollinated female flowers and viable tester pollen made it easy and quick to distinguish the two reactions. When two of the testers gave incompatible pollinations and all others were compatible, the two alleles in the female parent had been identified. Some pollinations gave inconclusive results, and the number of flowers on young trees was limited, so testing an introduced cultivar required 1 to 3 years for completion.

The OSU hazelnut breeding program collected germplasm as seeds from several countries, including Turkey, Georgia, Azerbaijan, Armenia, Russia, Ukraine, and Iran (Table 2).
Table 1. Pollen testers for incompatibility alleles in hazelnut.

\begin{tabular}{|c|c|c|c|}
\hline \multirow{2}{*}{$\frac{\text { Allele no. }}{1}$} & \multirow{2}{*}{$\begin{array}{r}\text { Tester }{ }^{2} \\
\text { 'Barcelona' }\end{array}$} & \multicolumn{2}{|c|}{ Alleles in tester (no.) $)^{\mathrm{y}}$} \\
\hline & & 1 & 2 \\
\hline 2 & OSU $20.058^{x}$ & $\underline{2}$ & $\underline{2}$ \\
\hline 3 & 'Nonpareil' & $\overline{1}$ & $\underline{\overline{3}}$ \\
\hline 4 & OSU 194.001 & 4 & $\overline{4}$ \\
\hline 5 & 'Badem' & $\overline{2}$ & $\overline{5}$ \\
\hline 6 & 'Henneman \#3' & $\underline{6}$ & $1 \overline{0}$ \\
\hline 7 & OSU 278.095 & $\overline{4}$ & 7 \\
\hline 8 & 'San Giovanni' & 2 & $\underline{\overline{8}}$ \\
\hline 9 & 'Segorbe' & $\underline{9}$ & $2 \overline{3}$ \\
\hline \multirow[t]{2}{*}{10} & 'Kargalak' & $\overline{2}$ & $\underline{10}$ \\
\hline & 'Gamma' & 2 & $\underline{10}$ \\
\hline 11 & OSU 278.121 & 4 & $\underline{11}$ \\
\hline 12 & OSU 55.077 & 2 & $\underline{12}$ \\
\hline 13 & 'Ashrafi' 1226.004 & $\underline{13}$ & $\overline{31}$ \\
\hline 14 & 'Gem' & $\overline{2}$ & 14 \\
\hline 15 & GN66(3)AF5 & 11 & $\overline{15}$ \\
\hline 16 & OSU 485.015 & 11 & $\underline{16}$ \\
\hline 17 & 'Mortarella' & 2 & $\overline{17}$ \\
\hline 18 & 'Neue Riesen' & $\underline{18}$ & $\overline{25}$ \\
\hline 19 & OSU 452.026 & $\overline{4}$ & $\underline{19}$ \\
\hline 20 & OSU 1038.084 & 2 & $\underline{20}$ \\
\hline 21 & OSU 168.026 & 2 & $\overline{21}$ \\
\hline 22 & OSU 937.069 & 4 & $\overline{22}$ \\
\hline 23 & OSU 385.006 & 4 & $\overline{23}$ \\
\hline \multirow[t]{2}{*}{24} & OSU 54.041 & 2 & $\overline{24}$ \\
\hline & OSU 1092.108 & 4 & $\underline{24}$ \\
\hline 25 & 'Ordu' & 4 & $\overline{25}$ \\
\hline 26 & OSU 447.015 & $\underline{26}$ & $\underline{26}$ \\
\hline \multirow[t]{2}{*}{27} & 'Buttner's Zeller' & $\overline{11}$ & $\overline{27}$ \\
\hline & OSU 962.014 & 4 & $\underline{27}$ \\
\hline 28 & OSU 562.031 & 26 & $\overline{28}$ \\
\hline 29 & OSU 930.081 & 4 & $\overline{29}$ \\
\hline 30 & OSU 1116.049 & 4 & $\overline{30}$ \\
\hline 31 & 'Ata Baba' & 4 & $\overline{31}$ \\
\hline 32 & 'Reka \#2' & 2 & $\underline{32}$ \\
\hline 33 & 'Ganja' & $\underline{4}$ & $\underline{33}$ \\
\hline
\end{tabular}

zTwo testers are used for some S-alleles.

${ }^{\mathrm{y}}$ Alleles expressed by the pollen are underlined.

${ }^{\mathrm{x}} \mathrm{OSU}=$ Oregon State University.

These countries represent the eastern part of the distribution of $C$. avellana. The seeds were stratified and planted in the greenhouse as root tips emerged 3 to 5 months later. Seedlings were grown in 3.8-L containers in a glasshouse the first summer and transplanted into the field in October. The S-alleles in the selections were identified using the same procedures as for the cultivars. Their flowering generally begins in the fourth year in the field. Before identification of their S-alleles, seedlings were selected for precocity, round nut shape, few defects, and few buds blasted by mites (primarily Phytoptus avellanae Nal.).

When a cultivar or selection representing a new pair of Salleles was identified, its pollen was placed on female inflorescences of two different cultivars or selections. Each expressed one of the two alleles in the new pair, the other allele being different. If one of these pollinations was compatible and the other incompatible, the allele common to both parents in the incompatible pollination was dominant to the 
Table 2. Origin of hazelnut seed lots by country, year and collection location, and the number of selections from each lot whose S-alleles were identified.

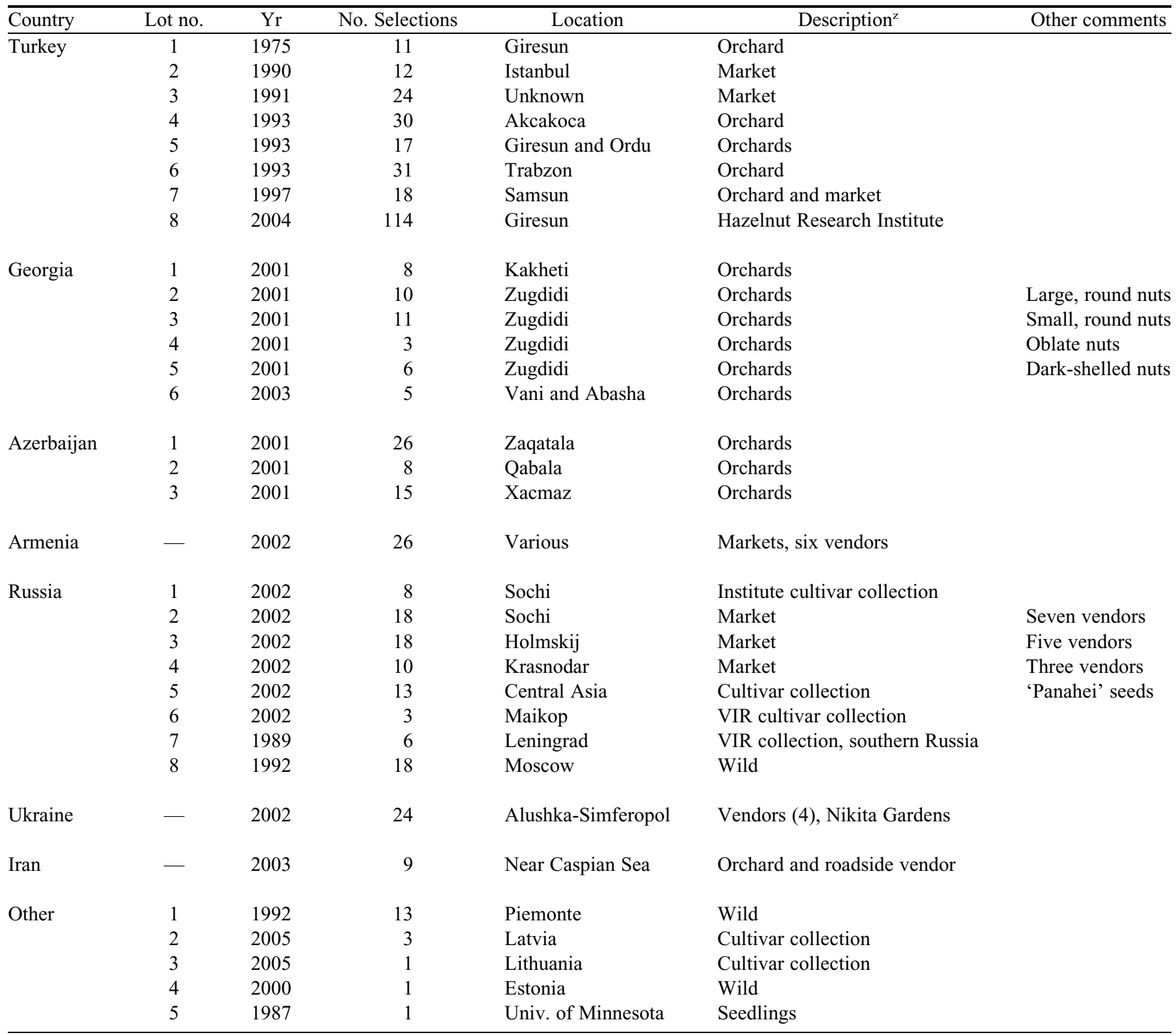

${ }^{\mathrm{z} V I R}=$ N.I. Vavilov Research Institute of Plant Industry.

other allele in the cultivar or selection being tested. If both pollinations were incompatible, the two alleles in the cultivar or selection were considered to be codominant in its pollen. Females of a third genotype expressing different alleles were pollinated to verify that the selection's pollen was viable.

If two of the testers gave incompatible pollinations and all others were compatible, the two alleles had been identified. A single incompatible reaction and 24 compatible reactions indicated either the presence of one known and one unknown allele or homozygosity. If pollen of a cultivar or selection was compatible on all known alleles, it was considered a potential tester for a novel S-allele. Testers that express the novel allele in their pollen and produce large quantities of pollen early in the season are preferred.

$\mathrm{S}_{28}$ from the cutleaf hazelnut, which gives self-compatible seedlings on some combinations (Mehlenbacher and Smith,
2006), was excluded from this study, because its presence cannot be detected by standard procedures.

Based on SSR markers, Boccacci et al. (2006) and Gökirmak et al. (2009) assigned most hazelnut accessions to one of four groups: Spanish-Italian, Central European, English, and Black Sea. SSR markers were used by Boccacci et al. (2008) to investigate cultivars in northeastern Spain and by Gürcan et al. (2010) to investigate cultivars in the Black Sea group. Cultivars previously fingerprinted with SSR markers (Boccacci et al., 2006, 2008; Gökirmak et al., 2009; Gürcan et al., 2010; S.A. Mehlenbacher, unpublished data) are listed by their assigned group. Other previously fingerprinted very diverse accessions that were not placed in one of the four main groups are presented as a group labeled "other." Accessions that had not yet been fingerprinted were placed in the most suitable group based on their geographic origin with consideration of morphological 


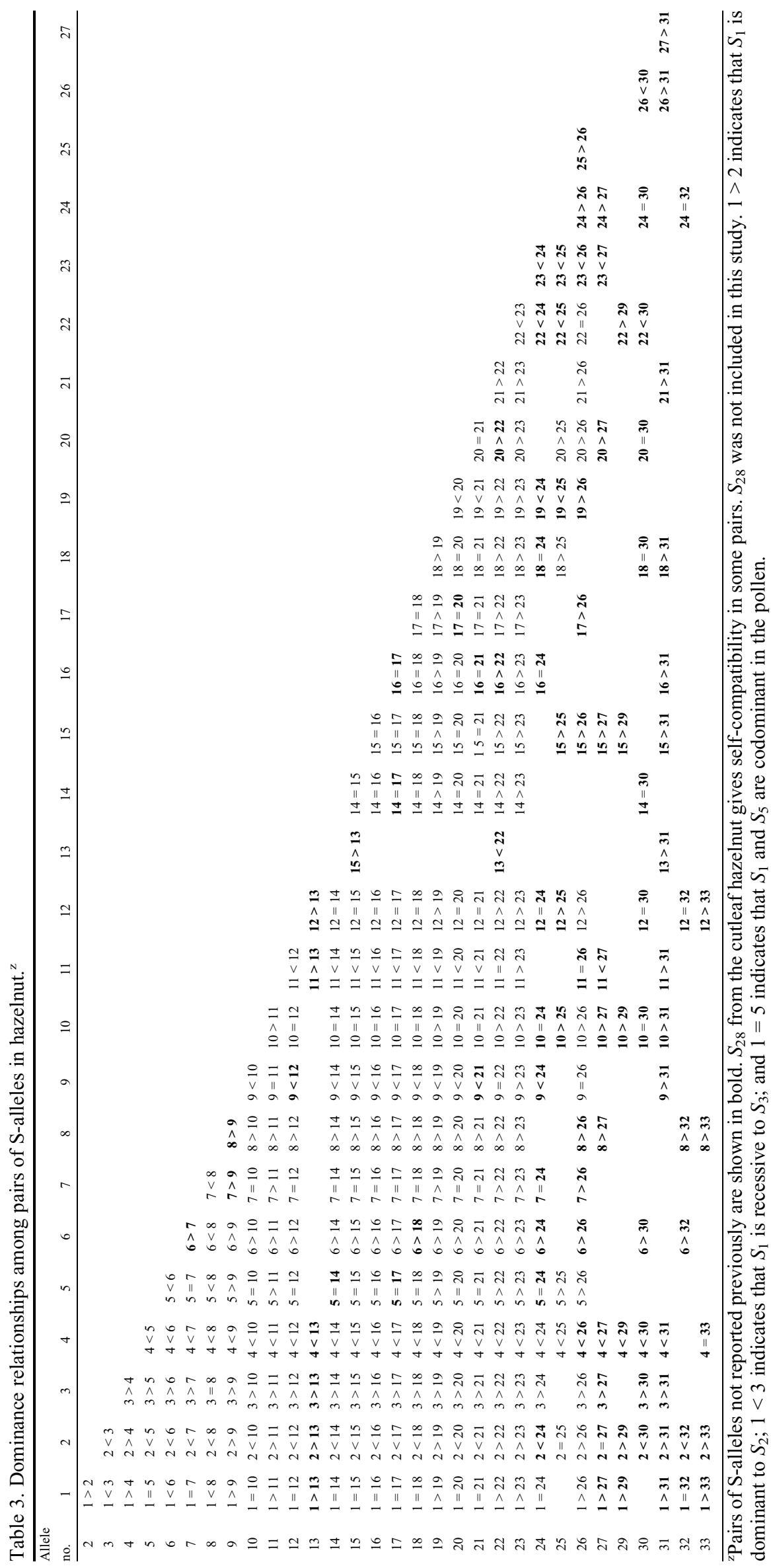


traits. Boccacci et al. (2006), Gökirmak et al. (2009), and Gürcan et al. (2010) identified the presumed parentage of several cultivars based on microsatellite markers.

Cultivars and selections were grouped by SSR marker profiles and geographic origin, and the most common alleles in each group were identified. The data were examined for differences in S-allele frequency associated with geographic origin. Variability in S-allele frequency among seed lots from the same country was also examined.

\section{Results}

New ALleles AND TeSTERS. Mehlenbacher (1997b) listed testers for $26 \mathrm{~S}$-alleles, including $S_{13}$ from the interspecific hybrids called "Chinese Trazels." In this study we identified six new alleles and a $C$. avellana tester for $S_{13}$ (Table 1). $\mathrm{S}_{27}$ is the dominant allele in 'Buttner's Zellernuss' $\left(S_{11} S_{27}\right)$. $S_{28}$ is present in 'Cutleaf' $\left(\mathrm{S}_{20} \mathrm{~S}_{28}\right)$, as mentioned previously but was excluded from this study. $S_{29}$, the dominant allele in tester OSU $930.081\left(S_{4} S_{29}\right)$, was inherited from Russian selection OSU $495.049\left(S_{22} S_{29}\right)$. The latter originated from seeds sent from the headquarters of the N.I. Vavilov Research Institute of Plant Industry in the city then called Leningrad. Most of the hazelnuts in Russia are grown in the south, from the Black Sea coast through the Caucasus Mountains to Krasnodar. We believe that the seeds sent to us originated in this region of southern Russia. $S_{30}$ was first detected in seedlings of 'The Shah' $\left(S_{14} S_{30}\right)$, which had been imported as scions from the United Kingdom. $\mathrm{S}_{30}$ was later detected in selections from Azerbaijan and Turkey. OSU $1116.049\left(S_{4} S_{30}\right)$, a selection from Azerbaijan, is the pollen tester for $S_{30}$. $S_{31}$ is the dominant allele in 'Ata Baba' $\left(S_{4} S_{31}\right)$, which is the leading cultivar in Azerbaijan. $S_{32}$ is the dominant allele in 'Reka \#2' $\left(S_{2} S_{32}\right)$ from Serbia. The most recent new allele, $S_{33}$, is a codominant allele in 'Ganja' $\left(S_{4} S_{33}\right)$ from Azerbaijan. A tester that expresses only $S_{33}$ in its pollen has not yet been identified. 'Ata Baba,' 'Reka \#2', and 'Ganja' are the pollen testers for $S_{31}, S_{32}$, and $S_{33}$, respectively. $S_{13}$, previously identified in "Chinese Trazels," was found in the 'Ashrafi' clone $1226.004\left(S_{13} S_{31}\right)$ from Azerbaijan. It was also detected in selection OSU $1168.130\left(S_{4} S_{13}\right)$, which originated from seeds purchased in the market in Holmskij, a village near Krasnodar, Russia, and in selection OSU 1090.042, which originated in a seed lot from Georgia. 'Ashrafi' and OSU 1168.130 are used as pollen testers, whereas the later-flowering 'Ashrafi' is also the female tester for $S_{13}$.

Dominance Relationships. Mehlenbacher (1997b) presented dominance relationships based on 233 pairs of alleles. We identified 105 new pairs of alleles (Table 3 ) and in this article show the relationships for 338 of the possible 496 pairs of alleles. The number of pairs was limited for the most recently identified alleles. In all pairs, both alleles were expressed in the stigmas, but often only one was expressed in the pollen because of dominance. A revised dominance hierarchy was drawn based on new data for pairs of alleles (Fig. 1). The dominance hierarchy is linear with eight levels (Mehlenbacher, 1997b). The relationships among four alleles $\left(S_{13}, S_{23}, S_{29}\right.$, and $\left.S_{31}\right)$ are unknown, so they are shown as adjacent boxes. All four are dominant to $S_{4}$ and recessive to one or more of the alleles at the next higher level $\left(S_{9}, S_{11}, S_{22}\right.$, and $\left.S_{26}\right)$.

S-ALLELES IN CULTIVARS. Mehlenbacher (2013) reported the alleles of 282 unique cultivars, including 112 from previous reports (Table 3). Cultivars with different names often have

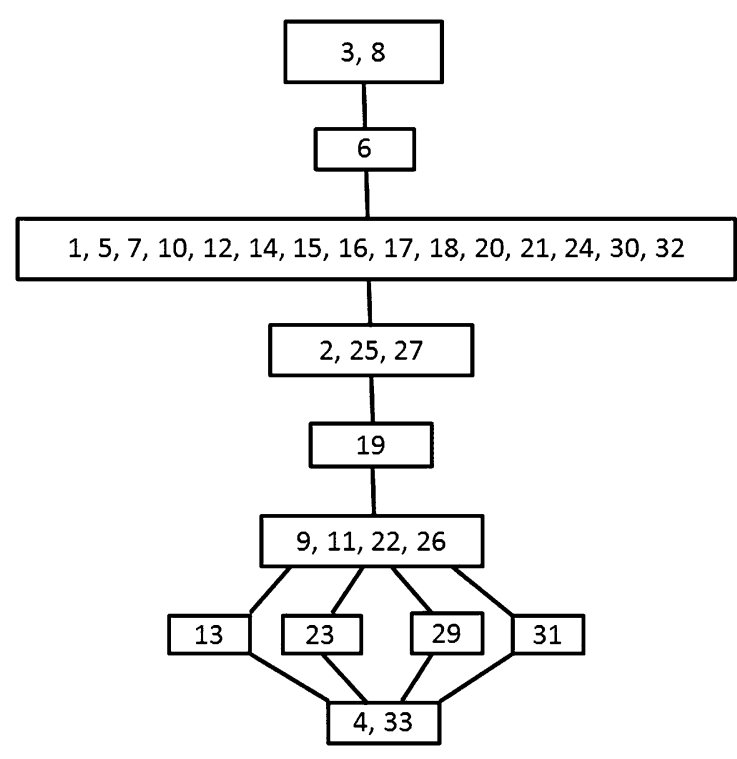

Fig. 1. Dominance hierarchy of S-alleles in hazelnut pollen. Alleles are dominant to alleles below them and codominant with those at the same level.

identical microsatellite marker fingerprints and S-alleles (Boccacci et al., 2006; Gökirmak et al., 2009; Gürcan et al., 2010), which leads to confusion. As a result, the number of unique genotypes in collections is often less than the number of names. Mehlenbacher (2013) listed cultivars with identical fingerprints and gave the preferred name for each. The Salleles of 13 interspecific hybrids are also listed.

Relationship of S-ALLELES TO GeOgRaPhic ORIGIN IN HAZELNUT CULTIVARS. Boccacci et al. (2006) and Gökirmak et al. (2009) assigned most hazelnut accessions to one of four groups: Spanish-Italian, Central European, English, and Black Sea. Other very diverse accessions that were not placed in one of the four main groups are presented as a group labeled "other" (Tables 4 and 5). Cultivars that have been fingerprinted with SSR markers (Boccacci et al., 2006; Gökirmak et al., 2009; S.A. Mehlenbacher, unpublished data) are listed as members of their assigned group. Accessions that have not yet been fingerprinted were placed in the most suitable group based on their geographic origin with consideration of morphological traits. The presumed parentage of several cultivars, based on microsatellite markers (Boccacci et al., 2006, 2008; Gökirmak et al., 2009; Gürcan et al., 2010), is listed (Table 4). The most frequent alleles in the 284 hazelnut cultivars (excluding interspecific hybrids) are: $S_{2}(13.9 \%), S_{1}(9.3 \%), S_{10}(8.5 \%), S_{5}(7.2 \%), S_{3}$ (6.2\%), $S_{4}(6.0 \%)$, and $S_{6}(5.3 \%)$. Percentages for all other alleles were less than $5.0 \%$. Half of the alleles had frequencies below $2 \%$. Allele frequencies differed among the cultivar groups. In the following paragraphs, alleles with frequencies greater than $4 \%$ are called common, alleles with frequencies between $2 \%$ and $4 \%$ are called rare, and alleles with frequencies less than $2 \%$ are called very rare.

The Spanish-Italian group contains 71 cultivars. The common alleles and their frequencies are: $S_{2}(30.3 \%), S_{1}(14.1 \%)$, $S_{10}(9.2 \%), S_{22}(7.8 \%), S_{17}(6.3 \%)$, and $S_{23}(4.9 \%)$. The common alleles reflect the importance of 'Barcelona' $\left(S_{1} S_{2}\right)$, 'Siciliana' (syn. 'Montebello') ( $\left.S_{1} S_{2}\right)$, 'Negret' $\left(S_{10} S_{22}\right)$, 'Segorbe' $\left(S_{9} S_{23}\right)$, and 'Tonda di Giffoni' $\left(S_{2} S_{23}\right)$ in this group. 
Table 4. S-alleles and origins of hazelnut cultivars by group.

\begin{tabular}{|c|c|c|c|c|c|}
\hline Group $^{z}$ & Cultivar & Origin & & les (no.) & Parentage \\
\hline Spanish-Italian & Alcover & Spain & $\underline{15}$ & 22 & \\
\hline Spanish-Italian & Amarillo & Chile & 2 & $\underline{6}$ & \\
\hline Spanish-Italian & Amarillo Tardio & Chile & $\underline{2}$ & $\underline{2}$ & \\
\hline Spanish-Italian & Badem & Turkey & $\overline{2}$ & $\underline{5}$ & \\
\hline Spanish-Italian & Barcelona & Spain & $\underline{1}$ & $\overline{2}$ & \\
\hline Spanish-Italian & Bianca & Italy & $\underline{\overline{2}}$ & $\overline{2}$ & \\
\hline Spanish-Italian & Camponica & Italy & $\overline{1}$ & $\overline{2}$ & \\
\hline Spanish-Italian & Casina & Spain & $\underline{10}$ & $\underline{21}$ & \\
\hline Spanish-Italian & Closca Molla & Spain & 2 & $\underline{5}$ & \\
\hline Spanish-Italian & Comen & Piemonte, Italy & $\underline{2}$ & $\overline{9}$ & \\
\hline Spanish-Italian & Comun & Portugal & $\underline{10}$ & Unknown & \\
\hline Spanish-Italian & Fitzgerald 20 & Oregon, U.S. & $\underline{\overline{2}}$ & 11 & \\
\hline Spanish-Italian & Francoli & Spain & $\underline{1 \overline{7}}$ & 22 & Negret $\times$ Tomasina $^{y}$ \\
\hline Spanish-Italian & Garrofi & Spain & $\overline{1}$ & $\underline{6}$ & \\
\hline Spanish-Italian & Ghirara & Italy & 2 & $\underline{2 \overline{1}}$ & \\
\hline Spanish-Italian & Gironell (Grossal) & Spain & $\underline{1}$ & $\overline{2}$ & \\
\hline Spanish-Italian & Gironenc Vermellet & Spain & $\overline{2}$ & $\underline{17}$ & \\
\hline Spanish-Italian & Grifoll & Spain & $\underline{2}$ & $\overline{22}$ & Negret $\times$ Morell $^{\mathrm{y}}$ \\
\hline Spanish-Italian & Gubener Barcelloner & Germany & $\underline{1}$ & 23 & \\
\hline Spanish-Italian & Iannusa Racinante & Italy & $\overline{1}$ & $\underline{8}$ & \\
\hline Spanish-Italian & Lluenta & Spain & $\underline{17}$ & $2 \overline{2}$ & Negret $\times$ Gironenc Vermellet $^{\mathrm{y}}$ \\
\hline Spanish-Italian & Lozovskoi Sharovidnyi & Ukraine & $\underline{2}$ & $\underline{25}$ & \\
\hline Spanish-Italian & Negret & Spain & $\underline{10}$ & $\overline{22}$ & \\
\hline Spanish-Italian & Nocchiolino Sangrato & Italy & $\frac{7}{1}$ & $\underline{17}$ & \\
\hline Spanish-Italian & Nociara & Italy & $\overline{1}$ & $\underline{3}$ & \\
\hline Spanish-Italian & Pauetet & Spain & $\underline{18}$ & $2 \overline{2}$ & Negret $\times$ Artellet $^{\mathrm{y}}$ \\
\hline Spanish-Italian & Pere Mas & Spain & $\overline{9}$ & $\underline{10}$ & \\
\hline Spanish-Italian & Pinyolenc \#1 & Spain & $\underline{2}$ & $\underline{2}$ & \\
\hline Spanish-Italian & Pinyolenc \#2 & Spain & $\overline{2}$ & $\underline{1 \overline{7}}$ & \\
\hline Spanish-Italian & Planeta & Spain & $\underline{1}$ & $\overline{2}$ & \\
\hline Spanish-Italian & Punxenc & Spain & $\overline{1}$ & $\underline{10}$ & Negret $\times$ unknown $^{\mathrm{w}}$ \\
\hline Spanish-Italian & Ratllada & Spain & $\underline{10}$ & $\overline{22}$ & \\
\hline Spanish-Italian & Ratoli & Spain & 2 & $\underline{10}$ & \\
\hline Spanish-Italian & Ribet & Spain & 2 & $\underline{16}$ & \\
\hline Spanish-Italian & Riccia di Talanico & Italy & $\underline{1}$ & $\overline{2}$ & \\
\hline Spanish-Italian & Römische Nuss & Italy (?) & $\underline{10}$ & $\underline{18}$ & \\
\hline Spanish-Italian & San Giovanni & Italy & $\overline{2}$ & $\underline{8}$ & \\
\hline Spanish-Italian & Sant Jaume & Spain & $\underline{1}$ & $\underline{1 \overline{7}}$ & Barcelona $\times$ Pinyolenc $\# 2^{y}$ \\
\hline Spanish-Italian & Sant Joan & Spain & $\underline{2}$ & $\underline{25}$ & \\
\hline Spanish-Italian & Sant Pere & Spain & $\underline{2 \overline{2}}$ & $\underline{26}$ & Negret $\times$ unknown ${ }^{y}$ \\
\hline Spanish-Italian & Segorbe & Spain & $\underline{9}$ & $\overline{23}$ & \\
\hline Spanish-Italian & Siciliana Montebello & Italy & $\underline{1}$ & 2 & \\
\hline Spanish-Italian & Simon & Spain & $\underline{6}$ & 22 & Negret $\times$ Garrofi $^{\mathrm{y}}$ \\
\hline Spanish-Italian & Tapparona di Mezzanego & Italy & $\overline{5}$ & 25 & \\
\hline
\end{tabular}


Table 4. Continued.



Continued next page 
Table 4. Continued.

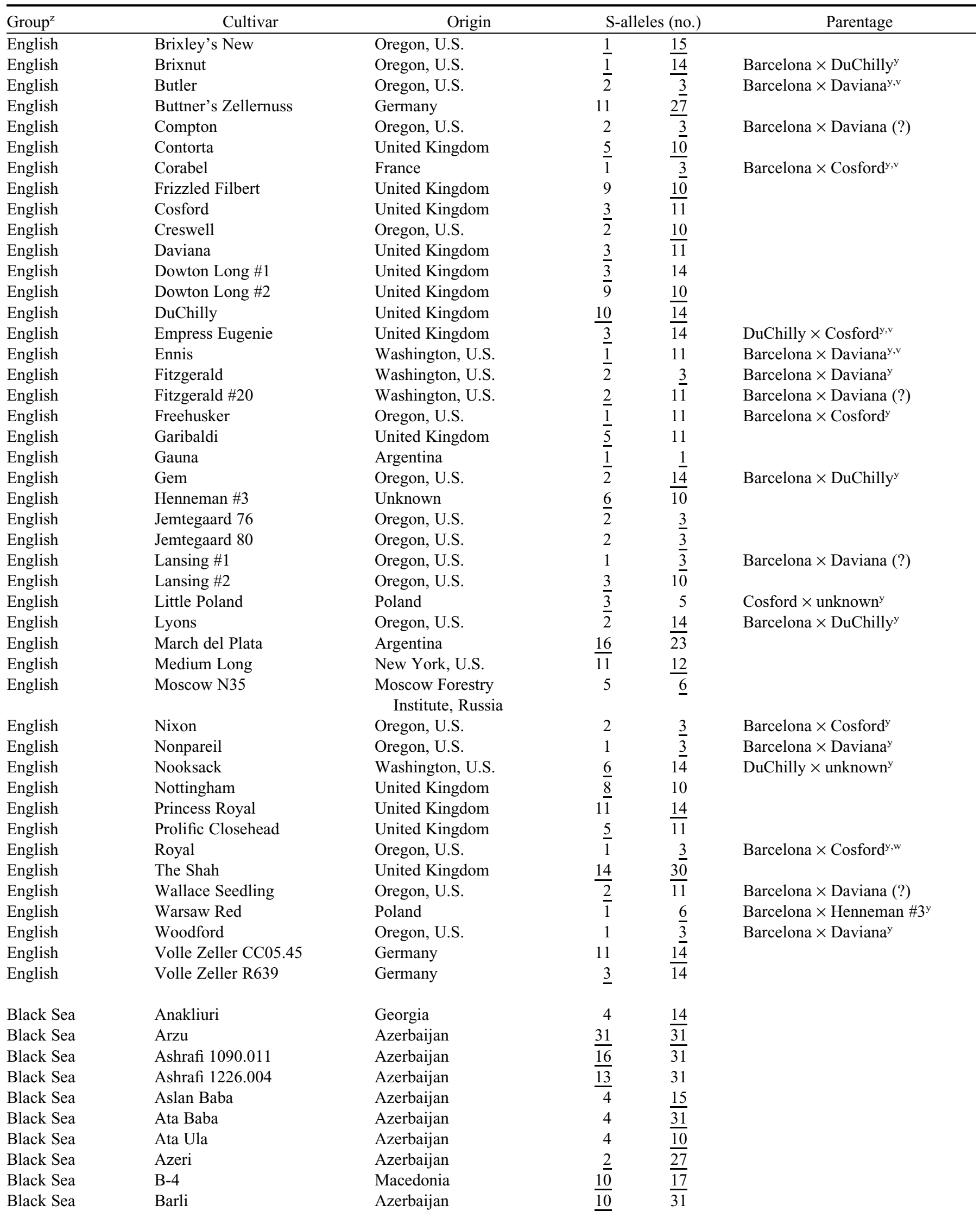


Table 4. Continued.




Table 4. Continued.

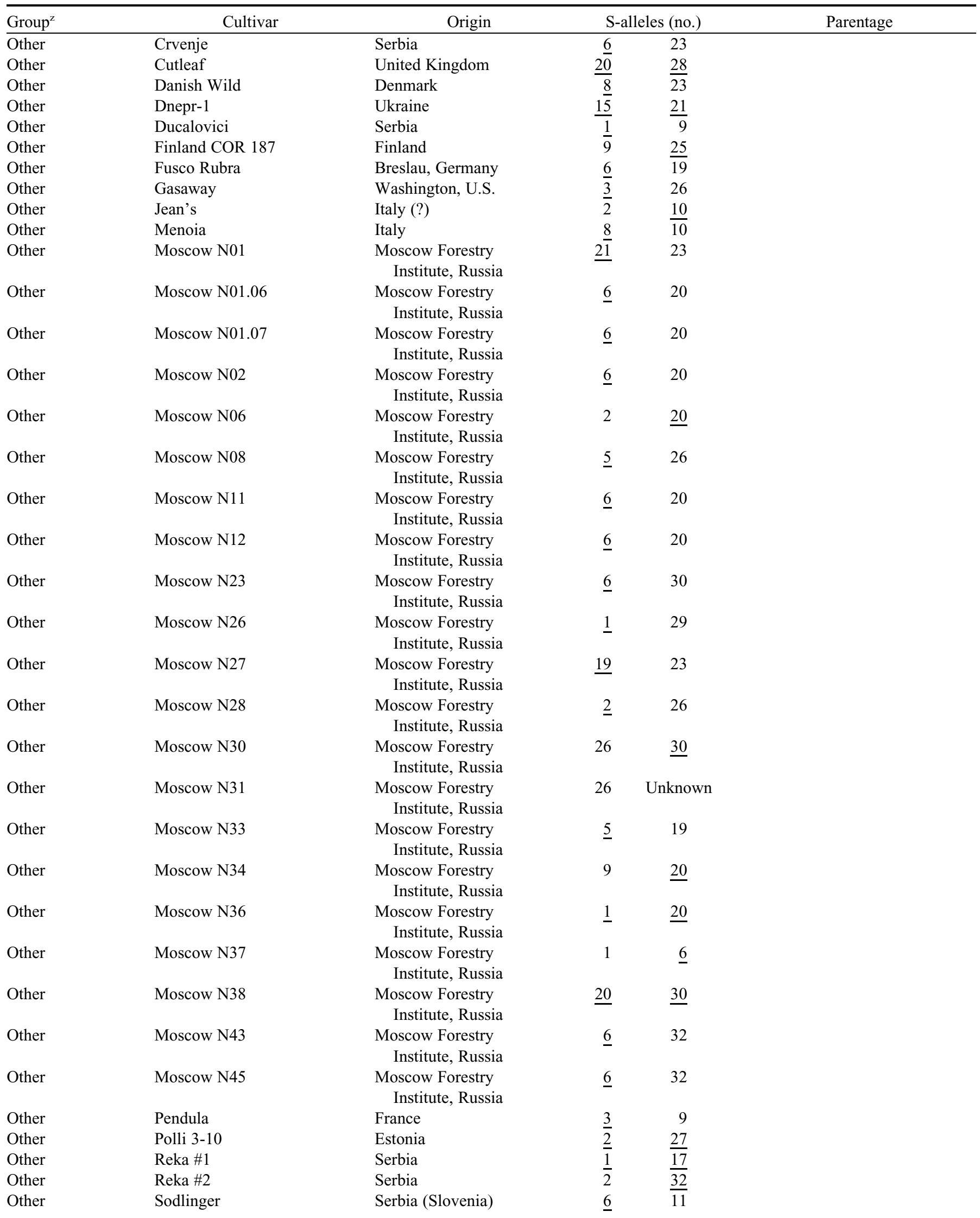


Table 4. Continued.




Table 4. Continued.

\begin{tabular}{|c|c|c|c|c|c|}
\hline Group $^{z}$ & Cultivar & Origin & & (no.) & Parentage \\
\hline $\begin{array}{c}\text { Interspecific } \\
\text { hybrids }\end{array}$ & Potomac & U.S. & $\underline{5}$ & $\underline{12}$ & Rush $\times$ DuChilly ${ }^{x}$ \\
\hline $\begin{array}{c}\text { Interspecific } \\
\text { hybrids }\end{array}$ & Reed & U.S. & $\underline{12}$ & $\underline{15}$ & Rush $\times$ Hall's Giant ${ }^{\mathrm{x}}$ \\
\hline
\end{tabular}

${ }^{{ }^{7} C u l t i v a r s ~ a s s i g n e d ~ t o ~ g r o u p s ~ b a s e d ~ p r i m a r i l y ~ o n ~ s i m p l e ~ s e q u e n c e ~ r e p e a t ~ a n a l y s i s ~(B o c c a c c i ~ e t ~ a l ., ~ 2006 ; ~ G o ̈ k i r m a k ~ e t ~ a l ., ~ 2009 ; ~ M e h l e n b a c h e r, ~}$ unpublished data) with consideration of morphology and geographic origin.

yParentage based on simple sequence repeat markers (Gökirmak et al., 2009).

${ }^{x}$ Parentage based on publications and/or breeder records.

wParentage based on simple sequence repeat markers (Boccacci et al., 2008).

vParentage based on simple sequence repeat markers (Boccacci et al., 2006).

uParentage based on simple sequence repeat markers (Gürcan et al., 2010).

tTapparona di San Colombano Cortemoli.

${ }^{\mathrm{s}} \mathrm{OSU}=$ Oregon State University breeding program.

The Central European group contains 38 cultivars. The most common alleles are $S_{5}(21.1 \%), S_{15}(14.5 \%), S_{25}(13.2 \%), S_{20}$ $(11.8 \%), S_{11}(9.2 \%), S_{6}(5.3 \%)$, and $S_{10}(5.3 \%)$. The common alleles reflect the importance of 'Hall's Giant' $\left(S_{5} S_{15}\right)$ and 'Early Long Zeller' $\left(S_{20} S_{25}\right)$ in this group, which also includes hybrids with the English cultivars Daviana $\left(S_{3} S_{11}\right)$ and Cosford $\left(S_{3} S_{11}\right)$.

The English group contains 57 cultivars. The most common alleles are $S_{3}(19.2 \%), S_{11}(13.8 \%), S_{14}(12.8 \%), S_{2}(11.7 \%), S_{10}$ $(9.6 \%)$, and $S_{5}(5.3 \%)$. The common alleles reflect the importance of English cultivars Daviana $\left(S_{3} S_{11}\right)$, Cosford $\left(S_{3}\right.$ $\left.S_{11}\right)$, and DuChilly $\left(S_{10} S_{14}\right)$. The group includes several hybrids between these three English cultivars and 'Barcelona' $\left(S_{1} S_{2}\right)$.

The Black Sea group contains 58 cultivars. The most common alleles and their frequencies are: $S_{4}(27.6 \%), S_{10}$ (15.5\%), $S_{2}(8.6 \%), S_{5}(8.6 \%)$, and $S_{31}(7.8 \%)$. The first four alleles had been reported earlier in Turkish cultivars (Erdoğan et al., 2005; Mehlenbacher, 1997b), whereas $S_{31}$ is common in cultivars from Azerbaijan.

To simplify discussion, all 47 other accessions were placed in a single very diverse group called "other." The most frequent alleles in this group were $S_{6}(16.0 \%), S_{20}(10.6 \%), S_{2}(8.5 \%), S_{1}$ $(7.5 \%), S_{26}(6.4 \%), S_{5}(5.3 \%)$, and $S_{9}(5.3 \%)$. This group includes the ornamentals 'Fusco Rubra', 'Aurea', 'Pendula', 'Cutleaf', and 21 selections from the Russian Research Institute of Forestry and Mechanization (Pushkino, Russian Federation). Half of the Moscow selections from Pushkino have red leaves. $S_{20}$ is common in the cold-hardy Central European types with large nuts [e.g., 'Early Long Zeller' $\left(S_{20} S_{25}\right)$ ] that were probably used as parents in Moscow. The high frequency of $S_{26}$ in this group is surprising, because its frequency is only $1.76 \%$ of the total in the 284 cultivars. $S_{26}$ may be common in the parents of the Moscow selections. To survive in Moscow, the parents and selections must be cold-hardy.

In the 23 cultivars and pollenizers released by the OSU breeding program, the most common alleles are $S_{1}(28.3 \%), S_{3}$ (19.6\%), $S_{2}(10.9 \%), S_{15}(8.7 \%), S_{8}(6.5 \%)$, and $S_{26}(6.5 \%)$, which reflects the contributions of 'Barcelona' $\left(S_{1} S_{2}\right)$, 'Montebello' $\left(S_{1} S_{2}\right)$, 'Daviana' $\left(S_{3} S_{11}\right)$, 'Tonda Gentile delle Langhe' $\left(S_{2} S_{7}\right)$, 'Hall's Giant' $\left(S_{5} S_{15}\right)$, 'Tombul Ghiaghli' $\left(S_{4} S_{8}\right)$, and 'Gasaway' $\left(S_{3} S_{26}\right)$.

INTERSPECIFIC HYBRIDS. The 13 interspecific hybrids include four C. americana Marsh. $\times$ C. avellana hybrids ('Bixby', 'Buchanan', 'Potomac', and 'Reed'), three C. heterophylla
Fisch. $\times$ C. avellana hybrids from Dalian, China, and six hybrids with C. colurna L. and C. avellana in their pedigrees. $S_{15}$ was present in all three Chinese Trazels.

S-ALLELES IN SELECTIONS. The S-alleles of 522 selections of diverse origin were determined and are presented by geographic origin (Table 6). The origin of the seed lots is listed (Table 2).

TuRKISH SELECTIONS. The S-alleles were determined for 258 selections in eight groups of Turkish origin (Table 7). Of these, 114 originated as seeds harvested in the collection block at the Hazelnut Research Institute in Giresun and the remainder from various orchards and markets. In the Turkish selections, $S_{4}$ was by far the most common allele, representing $30.2 \%$ of the total. $S_{4}$ was present in high frequency in all eight groups of Turkish selections. The second most common allele was $S_{12}$, which represented $10.7 \%$ of the total and was also present in all eight groups. The next most common alleles were $S_{8}(9.9 \%), S_{10}$ $(9.9 \%), S_{2}(7.8 \%)$, and $S_{16}(4.3 \%)$, which were present in eight, six, seven, and four groups, respectively. Rare alleles detected at frequencies of $2 \%$ to $4 \%$ include $S_{14}, S_{3}, S_{5}, S_{9}$, and $S_{25}$, which were present in four, four, five, five, and six groups, respectively. Of the 33 alleles so far identified, only three $\left(S_{23}\right.$, $S_{29}$, and $S_{31}$ ) were absent in the Turkish selections; 18 others were present at frequencies less than $2 \%$. The most common alleles in the selections are also present in Turkish cultivars, but the selections include a very large number of additional alleles present at low frequency.

Georgian Selections. Nuts were collected in orchards in the Republic of Georgia (Table 8). Selections in Groups 1 through 5 were from nuts collected in 2001 and selections in Group 6 were from nuts collected in 2003. Eight selections (Group 1) were from nuts collected in orchards in the inland area of Kakheti at the base of the Caucasus Mountains near the border with Azerbaijan. The other five groups were collected in orchards near the Black Sea coast; Groups 2 to 5 were collected near Zugdidi. In the 43 selections, the most frequent allele was $S_{4}(22.1 \%)$ followed by $S_{2}(11.6 \%), S_{10}(9.3 \%)$, and $S_{20}(8.1 \%)$. Four additional alleles $\left(S_{31}, S_{1}, S_{19}\right.$, and $\left.S_{27}\right)$ were present at frequencies of $4 \%$ to $6 \%$. Eight alleles were rare and present at frequencies of $2 \%$ to $4 \%\left(S_{8}, S_{14}, S_{3}, S_{5}, S_{6}, S_{11}, S_{18}\right.$, and $\left.S_{30}\right)$. Seven alleles were present at frequencies less than $2 \%$ and nine were absent. $S_{4}$ is present in 'Anakliuri', which is the most widely planted in Georgia.

AzERBaiJan SELECTIONS. Nuts were collected in orchards in three locations: Zaqatala, Qabala, and Xaçmaz. The cultivars 
Table 5. Frequency of S-alleles in hazelnut cultivars by group.

\begin{tabular}{|c|c|c|c|c|c|c|c|c|c|}
\hline \multirow[b]{3}{*}{ Allele } & \multicolumn{9}{|c|}{ Group } \\
\hline & \multicolumn{2}{|c|}{ Spanish-Italian } & & \multicolumn{2}{|c|}{ Central European } & \multicolumn{2}{|c|}{ English } & & Black Sea \\
\hline & (no.) & $(\%)$ & & (no.) & $(\%)$ & $\overline{\text { (no.) }}$ & $(\%)$ & (no.) & $(\%)$ \\
\hline$\overline{1}$ & 20 & 14.08 & & 0 & 0.00 & 12 & 12.77 & 1 & 0.86 \\
\hline 2 & 43 & 30.28 & & 2 & 2.63 & 11 & 11.70 & 10 & 8.62 \\
\hline 3 & 2 & 1.41 & & 2 & 2.63 & 18 & 19.15 & 1 & 0.86 \\
\hline 4 & 0 & 0.00 & & 1 & 1.32 & 0 & 0.00 & 32 & 27.59 \\
\hline 5 & 4 & 2.82 & & 16 & 21.05 & 5 & 5.32 & 10 & 8.62 \\
\hline 6 & 5 & 3.52 & & 4 & 5.26 & 4 & 4.26 & 1 & 0.86 \\
\hline 7 & 2 & 1.41 & & 0 & 0.00 & 0 & 0.00 & 0 & 0.00 \\
\hline 8 & 3 & 2.11 & & 0 & 0.00 & 1 & 1.06 & 3 & 2.59 \\
\hline 9 & 4 & 2.82 & & 1 & 1.32 & 2 & 2.13 & 1 & 0.86 \\
\hline 10 & 13 & 9.15 & & 4 & 5.26 & 9 & 9.57 & 18 & 15.52 \\
\hline 11 & 1 & 0.70 & & 7 & 9.21 & 13 & 13.83 & 1 & 0.86 \\
\hline 12 & 0 & 0.00 & & 2 & 2.63 & 1 & 1.06 & 4 & 3.45 \\
\hline 13 & 0 & 0.00 & & 0 & 0.00 & 0 & 0.00 & 1 & 0.86 \\
\hline 14 & 1 & 0.70 & & 0 & 0.00 & 12 & 12.77 & 3 & 2.59 \\
\hline 15 & 2 & 1.41 & & 11 & 14.47 & 1 & 1.06 & 2 & 1.72 \\
\hline 16 & 1 & 0.70 & & 1 & 1.32 & 1 & 1.06 & 2 & 1.72 \\
\hline 17 & 9 & 6.34 & & 0 & 0.00 & 0 & 0.00 & 4 & 3.45 \\
\hline 18 & 2 & 1.41 & & 1 & 1.32 & 1 & 1.06 & 2 & 1.72 \\
\hline 19 & 0 & 0.00 & & 1 & 1.32 & 0 & 0.00 & 0 & 0.00 \\
\hline 20 & 1 & 0.70 & & 9 & 11.84 & 0 & 0.00 & 1 & 0.86 \\
\hline 21 & 3 & 2.11 & & 0 & 0.00 & 0 & 0.00 & 1 & 0.86 \\
\hline 22 & 11 & 7.75 & & 0 & 0.00 & 0 & 0.00 & 0 & 0.00 \\
\hline 23 & 7 & 4.93 & & 1 & 1.32 & 1 & 1.06 & 1 & 0.86 \\
\hline 24 & 2 & 1.41 & & 2 & 2.63 & 0 & 0.00 & 2 & 1.72 \\
\hline 25 & 4 & 2.82 & & 10 & 13.16 & 0 & 0.00 & 1 & 0.86 \\
\hline 26 & 1 & 0.70 & & 0 & 0.00 & 0 & 0.00 & 0 & 0.00 \\
\hline 27 & 0 & 0.00 & & 0 & 0.00 & 1 & 1.06 & 1 & 0.86 \\
\hline 28 & 0 & 0.00 & & 0 & 0.00 & 0 & 0.00 & 0 & 0.00 \\
\hline 29 & 0 & 0.00 & & 0 & 0.00 & 0 & 0.00 & 0 & 0.00 \\
\hline 30 & 0 & 0.00 & & 0 & 0.00 & 1 & 1.06 & 0 & 0.00 \\
\hline 31 & 0 & 0.00 & & 0 & 0.00 & 0 & 0.00 & 9 & 7.76 \\
\hline 32 & 0 & 0.00 & & 0 & 0.00 & 0 & 0.00 & 0 & 0.00 \\
\hline 33 & 0 & 0.00 & & 0 & 0.00 & 0 & 0.00 & 3 & 2.59 \\
\hline Unknown & 1 & 0.70 & & 1 & 1.32 & 0 & 0.00 & 1 & 0.86 \\
\hline \multirow[t]{3}{*}{ Total } & 142 & 100.00 & & 76 & 100.00 & 94 & 100.00 & 116 & 100.00 \\
\hline & \multicolumn{6}{|c|}{ Group } & & & \\
\hline & \multicolumn{3}{|c|}{ Other } & & \multicolumn{2}{|c|}{ OSU releases $^{z}$} & & \multicolumn{2}{|c|}{ Total } \\
\hline Allele & & & $(\%)$ & & (no.) & $(\%)$ & & (no.) & $(\%)$ \\
\hline 1 & & & 7.45 & & 13 & 28.26 & & 53 & 9.33 \\
\hline 2 & & & 8.51 & & 5 & 10.87 & & 79 & 13.91 \\
\hline 3 & & & 3.19 & & 9 & 19.57 & & 35 & 6.16 \\
\hline 4 & & & 0.00 & & 1 & 2.17 & & 34 & 5.99 \\
\hline 5 & & & 5.32 & & 1 & 2.17 & & 41 & 7.22 \\
\hline 6 & & & 15.96 & & 1 & 2.17 & & 30 & 5.28 \\
\hline 7 & & & 1.06 & & 0 & 0.00 & & 3 & 0.53 \\
\hline 8 & & & 3.19 & & 3 & 6.52 & & 13 & 2.29 \\
\hline 9 & & & 5.32 & & 0 & 0.00 & & 13 & 2.29 \\
\hline 10 & & & 3.19 & & 1 & 2.17 & & 48 & 8.45 \\
\hline 11 & & & 1.06 & & 1 & 2.17 & & 24 & 4.23 \\
\hline 12 & & & 1.06 & & 1 & 2.17 & & 9 & 1.58 \\
\hline 13 & & & 0.00 & & 0 & 0.00 & & 1 & 0.18 \\
\hline 14 & & & 0.00 & & 0 & 0.00 & & 16 & 2.82 \\
\hline 15 & & & 2.13 & & 4 & 8.70 & & 21 & 3.70 \\
\hline 16 & & & 1.06 & & 0 & 0.00 & & 6 & 1.06 \\
\hline 17 & & & 2.13 & & 0 & 0.00 & & 15 & 2.64 \\
\hline
\end{tabular}

Continued next page 
Table 5. Continued.

\begin{tabular}{|c|c|c|c|c|c|c|}
\hline \multirow[b]{3}{*}{ Allele } & \multicolumn{4}{|c|}{ Group } & & \\
\hline & \multicolumn{2}{|c|}{ Other } & \multicolumn{2}{|c|}{ OSU releases ${ }^{z}$} & \multicolumn{2}{|c|}{ Total } \\
\hline & $\overline{\text { (no.) }}$ & $(\%)$ & $\overline{\text { (no.) }}$ & $(\%)$ & $\overline{\text { (no.) }}$ & $(\%)$ \\
\hline 18 & 0 & 0.00 & 0 & 0.00 & 6 & 1.06 \\
\hline 20 & 10 & 10.64 & 0 & 0.00 & 21 & 3.70 \\
\hline 21 & 2 & 2.13 & 2 & 4.35 & 7 & 1.23 \\
\hline 24 & 0 & 0.00 & 0 & 0.00 & 6 & 1.06 \\
\hline 25 & 1 & 1.06 & 0 & 0.00 & 16 & 2.82 \\
\hline 26 & 6 & 6.38 & 3 & 6.52 & 10 & 1.76 \\
\hline 27 & 1 & 1.06 & 0 & 0.00 & 3 & 0.53 \\
\hline 28 & 1 & 1.06 & 0 & 0.00 & 1 & 0.18 \\
\hline 29 & 1 & 1.06 & 0 & 0.00 & 1 & 0.18 \\
\hline Unknown & 1 & 1.06 & 0 & 0.00 & 4 & 0.70 \\
\hline Total & 94 & 100.00 & 46 & 100.00 & 568 & 100.00 \\
\hline
\end{tabular}

${ }^{\mathrm{z}} \mathrm{OSU}=$ Oregon State University.

grown in each location are different. The most common alleles in the selections were $S_{4}(29.6 \%), S_{31}(18.4 \%), S_{10}$ (14.3\%), $S_{18}(7.1 \%), S_{2}(6.1 \%)$, and $S_{24}(4.1 \%)$ (Table 9). Rare alleles present in frequencies of $2 \%$ to $4 \%$ included $S_{3}$, $S_{7}, S_{12}, S_{14}$, and $S_{19}$. Eight additional alleles were present at frequencies less than $2 \%$ and 12 were absent. The high frequency of $S_{4}$ and $S_{31}$ reflects the importance of 'Ata Baba' $\left(\mathrm{S}_{4} \mathrm{~S}_{31}\right)$ in the country. Fewer alleles were detected in selections from Azerbaijan than in selections from Turkey, Russia, and Georgia.

Armenian Selections. The S-alleles were identified in 26 selections (Table 6) that originated from seeds purchased in markets in 2002 by J. Postman of USDA-ARS-NCGR. The most common alleles were $S_{4}(17.3 \%), S_{2}$ and $S_{31}(11.5 \%$ each), $S_{3}(7.7 \%)$, and $S_{9}$ and $S_{26}(5.8 \%$ each). Rare alleles present at frequencies of $2 \%$ to $4 \%$ were $S_{7}, S_{16}, S_{18}, S_{20}, S_{25}, S_{27}$, and $S_{30}$. Six alleles were very rare and only detected in one selection each, whereas 12 alleles were absent. The most common alleles $\left(S_{4}\right.$ and $\left.S_{31}\right)$ are those of the most important cultivar in Azerbaijan, 'Ata Baba'.

Russian SELECTIONS. The most common alleles in the eight groups of Russian selections were $S_{4}(21.3 \%), S_{24}(10.6 \%), S_{10}$ $(8.5 \%), S_{5}(7.4 \%)$, and $S_{14}(4.3 \%)$, which were found in five, five, six, three, and two of the eight groups, respectively (Table 10). Groups 1 to 5 could be considered cultivated Russian types, whereas Groups 6 and 7 originated in germplasm collection blocks, and Group 8 represents selections grown from nuts collected in the wild near Moscow. $S_{4}, S_{24}$, and $S_{10}$ were very common in the cultivated Russian groups, reflecting the importance of 'Cherkesskii II' $\left(S_{4} S_{24}\right)$. Twelve rare alleles present at frequencies of $2 \%$ to $4 \%$ were $S_{2}, S_{6}, S_{15}, S_{17}, S_{19}$, $S_{3}, S_{8}, S_{11}, S_{18}, S_{26}, S_{20}$, and $S_{31}$. Only $S_{27}$ and $S_{33}$ were absent in the Russian selections, which overall were a very diverse population.

UKRAINIAN SELECTIONS. Nuts collected in the Crimea in 2002 gave 24 selections (Table 6). Of these, 21 were from nuts purchased from roadside vendors between Alushta and Simferopol, and three originated from seeds collected at the Nikita Botanical Garden in Yalta. Most of the nuts purchased from vendors were very small and may have been collected from the wild. The most common alleles in the Crimean selections were $S_{10}$ $(22.9 \%), S_{2}(12.5 \%), S_{25}(8.3 \%), S_{9}(8.3 \%), S_{3}$ and $S_{14}(6.3 \%$ each), $S_{16}, S_{21}, S_{22}$, and $S_{24}(4.2 \%$ each). Eight rare alleles were present at frequencies of $2 \%$ to $4 \%$, and 13 alleles were not detected.

IRANIAN SELECTIONS. Seeds were collected from a small orchard in a valley in the foothills of the Elburz Mountains south of the Caspian Sea in 2003. Additional seeds were purchased from a roadside vendor along the main highway in the Talesh Mountains west of Astara. These seed lots gave six and three selections, respectively. Only four alleles were detected in the nine selections (Table 6): $S_{2}(55.6 \%), S_{33}$ $(27.8 \%), S_{8}(11.1 \%)$, and $S_{4}(5.6 \%)$.

OTher Selections. Of the 19 selections in the miscellaneous group labeled "other" (Table 6), 13 were from seeds collected in the wild in 1990 or 1992 in northern Italy. Three were from nuts collected in Latvia, one from Lithuania, and one from Estonia. Nuts from the University of Minnesota, likely of Scandinavian origin, gave rise to selection OSU 408.040. The most common alleles in this miscellaneous group were $S_{9}(15.9 \%), S_{5}$ and $S_{6}\left(10.5 \%\right.$ each), and $S_{10}$ and $S_{15}(7.9 \%$ each). Rare alleles detected once or twice were: $S_{2}, S_{4}, S_{7}, S_{12}$, $S_{14}, S_{16}, S_{18}, S_{19}, S_{23}, S_{24}, S_{27}$, and $S_{30}$. Twelve alleles were not detected.

Differences were noted in allele frequency between cultivars and selections (Table 11). $S_{4}$ was much more common in the selections than in the cultivars, whereas $S_{1}$ and $S_{2}$ were more common in the cultivars than in the selections.

\section{Discussion}

Relationship OF S-ALleles to GEOgRAPHIC ORIGIN IN HAZELNUT CULTIVARS. Boccacci et al. (2006), Gökirmak et al. (2009), and Gürcan et al. (2010) assigned most hazelnut 
Table 6. S-alleles in hazelnut selections originating from seeds collected in several countries. ${ }^{\mathrm{z}}$

\begin{tabular}{|c|c|c|c|c|c|c|c|c|c|c|c|}
\hline \multirow[b]{2}{*}{ Allele no. } & \multicolumn{8}{|c|}{ Country } & \multicolumn{2}{|c|}{ Total } & \multirow{2}{*}{$\begin{array}{c}\text { Countries in which } \\
\text { present (no.) }\end{array}$} \\
\hline & Turkey & Georgia & Azerbaijan & Armenia & Russia & Ukraine & Iran & Other & (no.) & $(\%)$ & \\
\hline 1 & 8 & 4 & 0 & 1 & 3 & 0 & 0 & 0 & 16 & 1.53 & 4 \\
\hline 2 & 40 & 10 & 6 & 6 & 7 & 6 & 10 & 1 & 86 & 8.24 & 8 \\
\hline 4 & 156 & 19 & 29 & 9 & 40 & 1 & 1 & 1 & 256 & 24.52 & 8 \\
\hline 5 & 12 & 2 & 1 & 0 & 14 & 1 & 0 & 4 & 34 & 3.26 & 6 \\
\hline 6 & 4 & 2 & 1 & 1 & 7 & 1 & 0 & 4 & 20 & 1.92 & 7 \\
\hline 8 & 51 & 3 & 1 & 1 & 5 & 1 & 2 & 0 & 64 & 6.13 & 7 \\
\hline 9 & 11 & 1 & 1 & 3 & 3 & 4 & 0 & 6 & 29 & 2.78 & 7 \\
\hline 10 & 51 & 8 & 14 & 0 & 16 & 11 & 0 & 3 & 103 & 9.87 & 6 \\
\hline 11 & 1 & 2 & 0 & 0 & 5 & 1 & 0 & 0 & 9 & 0.86 & 4 \\
\hline 12 & 55 & 0 & 2 & 1 & 1 & 0 & 0 & 1 & 60 & 5.75 & 5 \\
\hline 13 & 1 & 1 & 0 & 0 & 1 & 0 & 0 & 0 & 3 & 0.29 & 3 \\
\hline 18 & 3 & 2 & 7 & 2 & 5 & 0 & 0 & 1 & 20 & 1.92 & 6 \\
\hline 19 & 5 & 4 & 3 & 0 & 6 & 1 & 0 & 1 & 20 & 1.92 & 6 \\
\hline 20 & 2 & 7 & 0 & 2 & 4 & 0 & 0 & 0 & 15 & 1.44 & 4 \\
\hline 21 & 9 & 1 & 0 & 1 & 1 & 2 & 0 & 2 & 16 & 1.53 & 6 \\
\hline 22 & 7 & 0 & 1 & 0 & 2 & 2 & 0 & 2 & 14 & 1.34 & 5 \\
\hline 23 & 0 & 0 & 0 & 0 & 3 & 1 & 0 & 1 & 5 & 0.48 & 3 \\
\hline 24 & 2 & 1 & 4 & 1 & 20 & 2 & 0 & 1 & 31 & 2.97 & 7 \\
\hline 25 & 11 & 1 & 1 & 2 & 2 & 4 & 0 & 2 & 23 & 2.20 & 7 \\
\hline 26 & 5 & 0 & 0 & 3 & 5 & 0 & 0 & 0 & 13 & 1.25 & 3 \\
\hline 27 & 2 & 4 & 0 & 2 & 0 & 0 & 0 & 1 & 9 & 0.86 & 4 \\
\hline 28 & 0 & 0 & 0 & 0 & 0 & 0 & 0 & 0 & 0 & 0.00 & 0 \\
\hline
\end{tabular}

${ }^{\mathrm{z}}$ Shown for each S-allele are the counts of the number of seedlings with that allele.

accessions to one of four groups based on microsatellite marker fingerprints: Spanish-Italian, Central European, English, and Black Sea. We present the S-alleles of cultivars and selections by group. Accessions that had not yet been fingerprinted were placed in the most suitable group based on their geographic origin with consideration of morphological traits. Other very diverse accessions that were not placed in one of the four main groups are presented as a group labeled "other." The most frequent alleles in the 284 hazelnut cultivars (excluding interspecific hybrids) are $S_{2}, S_{1}, S_{10}, S_{5}, S_{3}$, and $S_{4}$. Percentages for all other alleles were less than $6.0 \%$. Many alleles were detected but at low frequency; half of the alleles had frequencies below $2 \%$. There were striking differences in S-allele frequencies among the cultivar groups (Table 5).

In the Spanish-Italian group, the most common alleles are $S_{2}$, $S_{1}, S_{10}, S_{22}$, and $S_{17}$. The first four reflect the importance of 'Barcelona' $\left(S_{1} S_{2}\right)$, 'Siciliana' [syn. 'Montebello' $\left(S_{1} S_{2}\right)$ ], and 'Negret' $\left(S_{10} S_{22}\right)$ in this group. In the Central European group, the most common alleles are $S_{5}, S_{15}, S_{25}, S_{20}$, and $S_{11}$. This reflects the importance of 'Hall's Giant' $\left(S_{5} S_{15}\right)$, 'Early Long Zeller' $\left(S_{20} S_{25}\right)$, and 'Pallagrossa' $\left(S_{5} S_{25}\right)$. The German group includes several hybrids between German cultivars with the English cultivars Daviana $\left(S_{3} S_{11}\right)$ and Cosford $\left(S_{3} S_{11}\right)$, which accounts for the high frequency of $S_{11}$. Three Polish cultivars in this group (Frango \#2, Frango \#5, and Volski Round) were determined by Gökirmak et al. (2009) to be seedlings of 'Cosford'. In the English group, the most common alleles are $S_{3}, S_{11}, S_{1}, S_{14}, S_{2}$, and $S_{10}$. The common alleles reflect the importance of the English cultivars Daviana, Cosford, and DuChilly $\left(S_{10} S_{14}\right)$. Several cultivars in this group are hybrids between English cultivars and 'Barcelona' $\left(S_{1} S_{2}\right)$, which accounts for the high frequencies of $S_{1}$ and $S_{2}$. Several cultivars selected by growers in the Pacific Northwestern United States appear to be hybrids of 'Barcelona' and 'Daviana' ('Butler', 'Ennis', 'Fitzgerald', 'Nonpareil', and 'Woodford' and probably also 'Compton', 'Fitzgerald \#20', 'Lansing \#1', and 'Wallace Seedling'). An additional three grower selections ('Freehusker', 'Nixon', and 'Royal') and the French cultivar Corabel are hybrids between 'Barcelona' and 'Cosford', 
Table 7. Frequency of S-alleles in hazelnut selections originating in eight seed lots collected in Turkey.

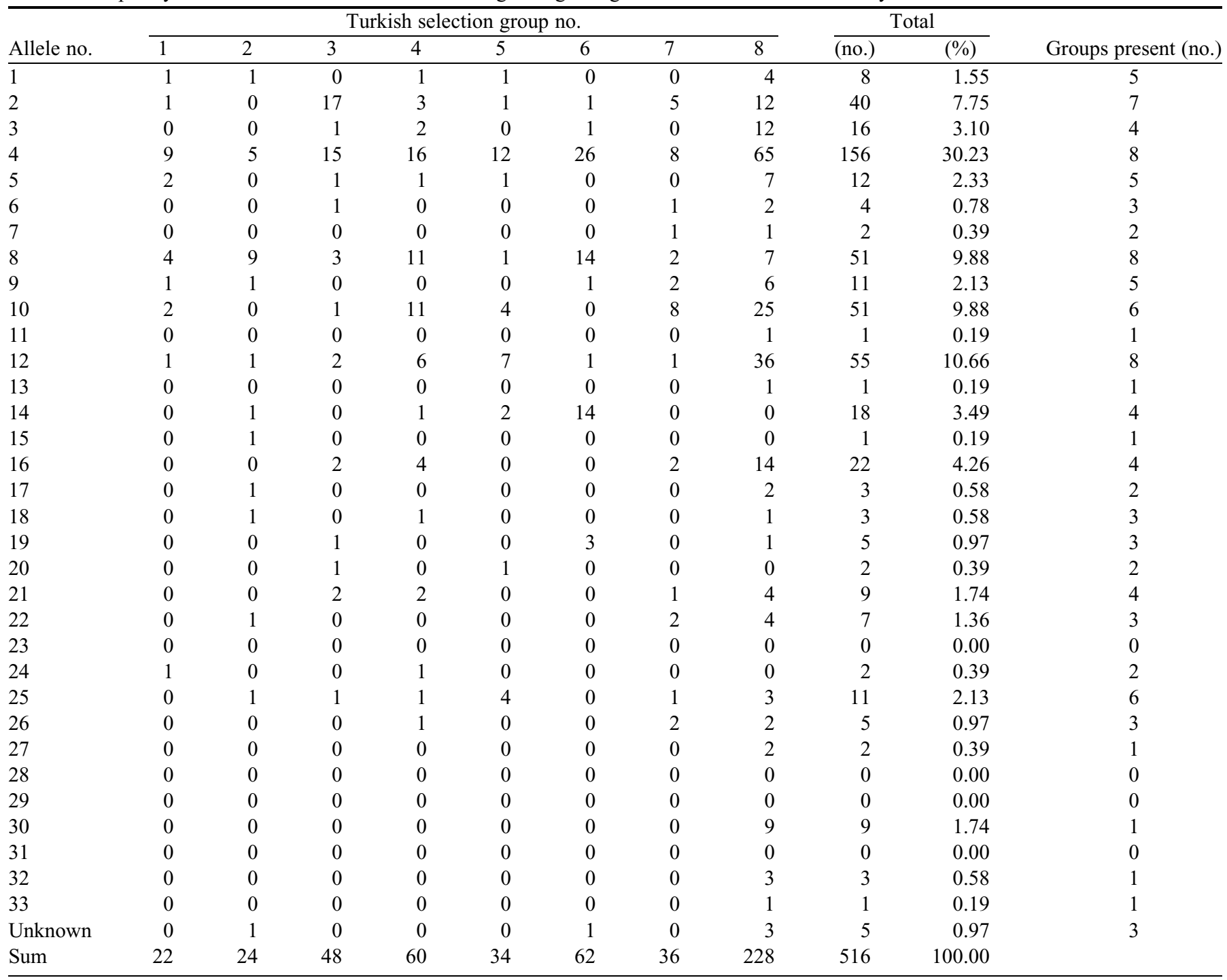

whereas three grower selections ('Brixnut', 'Gem', and 'Lyons') are hybrids between 'Barcelona' and 'DuChilly'. These grower selections were placed in the English group because of their English parents. In the Black Sea group, the most common alleles in cultivars are $S_{4}, S_{10}, S_{2}, S_{5}$, and $S_{31}$. The first four of these alleles had been reported earlier in Turkish cultivars (Erdoğan et al., 2005; Mehlenbacher, 1997b), including 'Tombul' $\left(S_{4} S_{12}\right)$, 'Sivri' $\left(S_{8} S_{10}\right)$, 'Mincane' $\left(S_{4} S_{8}\right)$, 'Palaz' $\left(S_{2} S_{4}\right)$, 'Kargalak' $\left(S_{2} S_{10}\right)$, and 'Yassi Badem' $\left(S_{2} S_{5}\right)$. Erdoğan et al. (2005) reported S-alleles expressed in pollen of Turkish cultivars. $S_{4}$, which is at the bottom of the dominance hierarchy (Fig. 1), is likely the second allele in several Turkish cultivars but is not expressed in their pollen. $S_{31}$ is present in 'Ata Baba' $\left(S_{4} S_{31}\right)$ and is common in other cultivars from Azerbaijan. In the other 45 accessions, the most frequent alleles were $S_{6}, S_{20}, S_{1}, S_{2}$, and $S_{26}$. This group includes several ornamentals and 21 selections from a forestry institute near Moscow, Russia. Half of the Moscow selections have red leaves. In breeding, two sources of red leaves have been used: 'Fusco Rubra' $\left(S_{6} S_{19}\right)$ and 'Rode Zeller' $\left(S_{6} S_{11}\right)$. In C. avellana, red leaf color is conferred by a dominant allele at the anthocyanin locus, which is linked to the S-locus (Thompson, 1985). Given the presence of $S_{6}$ in both redleaf parents and the linkage of $S_{6}$ with the allele for leaf anthocyanin, the high frequency of $S_{6}$ is not surprising. $S_{20}$ is common in the cold-hardy Central European types with large nuts [e.g., 'Early Long Zeller' $\left(S_{20}\right.$ $S_{25}$ )] that were probably used as parents in Moscow. The high frequency of $S_{26}$ in this "other" group is surprising, because its overall frequency in the 284 cultivars is only $1.8 \%$.

S-ALLELES IN TuRKiSH SELECTIONS. Large differences in Sallele frequency were seen among the groups as well as among seed lots within a group. In the Turkish selections, $S_{4}$ was by far the most common allele, representing $30.2 \%$ of the total. It was present in high frequency in all eight groups of selections. The second most common allele, $S_{12}$, represented $10.7 \%$ of the total. $S_{12}$ is present in 'Extra Ghiaghli' $\left(S_{4} S_{12}\right)$, which is a clone of the important cultivar Tombul. The next most common alleles were $S_{8}, S_{10}, S_{2}$, and $S_{16}$. Of the six most common alleles, five had been reported in Turkish cultivars, whereas the high frequency of $S_{16}$ was unexpected. Four rare alleles detected at frequencies of $2 \%$ to $4 \%\left(S_{14}, S_{3}, S_{9}\right.$, and $\left.S_{25}\right)$ had not been previously reported for Turkish cultivars, whereas $S_{5}$ is present in 'Yassi 
Table 8. Frequency of S-alleles in hazelnut selections originating in six seed lots collected in Georgia.

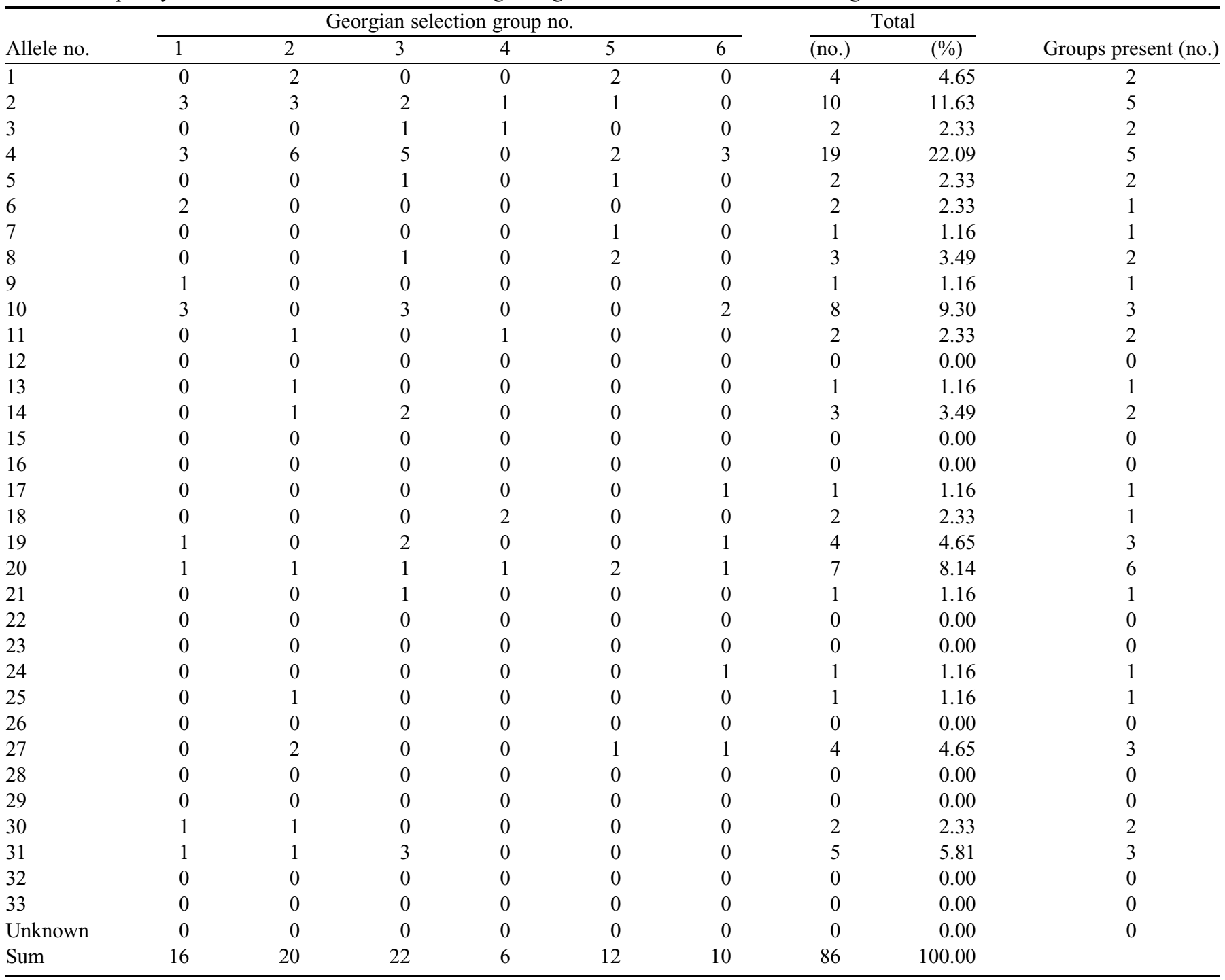

Badem'. Three alleles $\left(S_{23}, S_{29}\right.$, and $\left.S_{31}\right)$ were absent in the Turkish selections, and 18 others were present at frequencies less than 2\%. 'Ata Baba' $\left(S_{4} S_{31}\right)$, the leading cultivar in Azerbaijan, has more vigorous and upright growth than the leading Turkish cultivars, but its nuts, husks, and kernels are very similar. Given the common ethnic origin of the people in the two countries and extensive trade over many centuries, it was surprising to find $S_{31}$ absent in the Turkish selections. Differences in allele frequency among the eight Turkish seed lots were apparent. $S_{8}$ was very common in Group 4 from Akçakoca and Group 6 from Trabzon. $S_{10}$ was common in Group 4. $S_{14}$ was common in Group 6 but in no other Turkish group. $S_{16}$ and $S_{25}$ were especially common in Group 8 from the Hazelnut Research Institute. Alleles $S_{27}$ to $S_{33}$ are recorded as absent in Groups 1 to 7 of the Turkish selections (Table 7). However, we note that testers for these alleles were not available at the time that selections in Groups 1 to 7 were typed, and few selections from these groups have been preserved in our permanent collection. New alleles low in the dominance hierarchy $\left(S_{27}, S_{29}, S_{31}\right.$, and $\left.S_{33}\right)$ may indeed be present in selections in Groups 1 to 7 but not detected because they were not expressed in the pollen. However, $S_{30}$ and $S_{32}$ are high in the dominance hierarchy. Their presence would have been detected in selections in Groups 1 to 7 because only one other allele would have been identified, and their pollen would have been compatible on females expressing all other alleles. New testers would have been identified if $S_{30}$ or $S_{32}$ had been present in Turkish selections Groups 1 to 7 . In summary, the Turkish selections showed great diversity with respect to their S-alleles and differences in S-allele frequency among groups.

Selections from the Caucasus. In the 43 selections from Georgia, the most frequent alleles were $S_{4}, S_{2}, S_{10}, S_{20}$, and $S_{31}$. Three of these alleles are present in the Georgian cultivars (Table 8), but not $S_{2}$. It is likely that $S_{31}$ was contributed by 'Ata Baba' $\left(S_{4} S_{31}\right)$ from neighboring Azerbaijan. An additional 18 alleles were detected at frequencies of $1 \%$ to $5 \%$, indicating great diversity in the alleles present, whereas nine were absent. $S_{4}$ is present in four Georgian cultivars, including Anakliuri $\left(S_{4}\right.$ $S_{14}$ ), which is the most widely planted. Of three selected seedlings of 'Khachapura' $\left(S_{3} S_{18}\right)$, which has oblate nuts, two had $S_{18}$ and the other had $S_{3}$. In selections from Azerbaijan, 
Table 9. Frequency of S-alleles in hazelnut selections originating in three seed lots collected in Azerbaijan.

\begin{tabular}{|c|c|c|c|c|c|}
\hline \multirow[b]{2}{*}{ Allele no. } & \multicolumn{3}{|c|}{ Azerbaijan group no. } & \multicolumn{2}{|c|}{ Total } \\
\hline & 1 & 2 & 3 & (no.) & $(\%)$ \\
\hline 1 & 0 & 0 & 0 & 0 & 0.00 \\
\hline 2 & 1 & 0 & 5 & 6 & 6.12 \\
\hline 3 & 1 & 1 & 0 & 2 & 2.04 \\
\hline 4 & 15 & 6 & 8 & 29 & 29.59 \\
\hline 5 & 0 & 0 & 1 & 1 & 1.02 \\
\hline 6 & 0 & 0 & 1 & 1 & 1.02 \\
\hline 7 & 1 & 1 & 1 & 3 & 3.06 \\
\hline 8 & 1 & 0 & 0 & 1 & 1.02 \\
\hline 9 & 1 & 0 & 0 & 1 & 1.02 \\
\hline 10 & 4 & 3 & 7 & 14 & 14.29 \\
\hline 11 & 0 & 0 & 0 & 0 & 0.00 \\
\hline 12 & 0 & 1 & 1 & 2 & 2.04 \\
\hline 13 & 0 & 0 & 0 & 0 & 0.00 \\
\hline 14 & 1 & 1 & 0 & 2 & 2.04 \\
\hline 15 & 0 & 0 & 0 & 0 & 0.00 \\
\hline 16 & 1 & 0 & 0 & 1 & 1.02 \\
\hline 17 & 0 & 0 & 0 & 0 & 0.00 \\
\hline 18 & 7 & 0 & 0 & 7 & 7.14 \\
\hline 19 & 0 & 2 & 1 & 3 & 3.06 \\
\hline 20 & 0 & 0 & 0 & 0 & 0.00 \\
\hline 21 & 0 & 0 & 0 & 0 & 0.00 \\
\hline 22 & 1 & 0 & 0 & 1 & 1.02 \\
\hline 23 & 0 & 0 & 0 & 0 & 0.00 \\
\hline 24 & 2 & 0 & 2 & 4 & 4.08 \\
\hline 25 & 1 & 0 & 0 & 1 & 1.02 \\
\hline 26 & 0 & 0 & 0 & 0 & 0.00 \\
\hline 27 & 0 & 0 & 0 & 0 & 0.00 \\
\hline 28 & 0 & 0 & 0 & 0 & 0.00 \\
\hline 29 & 0 & 0 & 0 & 0 & 0.00 \\
\hline 30 & 0 & 0 & 1 & 1 & 1.02 \\
\hline 31 & 15 & 1 & 2 & 18 & 18.37 \\
\hline 32 & 0 & 0 & 0 & 0 & 0.00 \\
\hline 33 & 0 & 0 & 0 & 0 & 0.00 \\
\hline Unknown & 0 & 0 & 0 & 0 & 0.00 \\
\hline Sum & 52 & 16 & 30 & 98 & 100.00 \\
\hline
\end{tabular}

the most common alleles, $S_{4}$ and $S_{31}$, were present in all three locations (Zaqatala, Qabala, and Xaçmaz). Zaqatala, located at the base of the Caucasus Mountains not far from the Georgian border, is the most important production zone. There, 'Ata Baba' $\left(S_{4} S_{31}\right)$ is the most important cultivar. The third common allele $\left(S_{10}\right)$ is present in several cultivars from Azerbaijan. An additional 17 alleles were present at frequencies of $1 \%$ to $7 \%$, and 12 were absent. Twenty S-alleles were found in the Azeri selections, which is fewer than in selections from Turkey, Russia, and Georgia. Hazelnut orchards were established during the Soviet era on state and collective farms. All aspects of production, including the choice of cultivars and pollenizers, were chosen by government officials. Most of the nuts from Azerbaijan were collected in such orchards. The most common alleles in the Armenian selections, all from nuts purchased in markets, were $S_{4}, S_{2}, S_{31}, S_{3}, S_{9}$, and $S_{26}$. The common alleles $S_{4}$ and $S_{31}$ are those of 'Ata Baba', the most important cultivar in Azerbaijan. The presence of rare allele $S_{31}$ in high frequency in all three former Soviet republics in the Caucasus indicates probable sharing of plant material. The level of diversity in
Armenian selections is similar to that observed in selections from Azerbaijan.

Russia AND UKraine. Taken as a whole, the Russian selections were very diverse. The most common alleles in the eight groups of Russian selections were $S_{4}, S_{24}, S_{10}$, and $S_{5}$. The first two alleles are present in 'Cherkesskii II' $\left(S_{4} S_{24}\right)$, which is the most important cultivar in the north Caucasus. In the Crimea (Ukraine), hazelnut is cultivated to a very limited extent in the protected, mild climate on the south coast of the peninsula. Most of the nuts purchased from vendors were very small and may have been collected from the wild. The six most common alleles in the 24 Crimean selections were $S_{10}, S_{2}, S_{25}$, $S_{9}, S_{3}$, and $S_{14}$. Twelve rare alleles were present at frequencies of $2 \%$ to $5 \%$, and 13 alleles were not detected. The Crimean selections showed fewer S-alleles than the Russian, Georgian, and Turkish selections.

IRAN. Only four alleles were detected in the Iranian selections: $S_{2}, S_{33}, S_{8}$, and $S_{4}$. The number of alleles was strikingly less than in selections from other countries. $S_{33}$ is a very rare allele present in 'Ganja' $\left(S_{4} S_{33}\right)$ from Azerbaijan and very few selections, so it was surprising that $S_{33}$ accounted for $27.8 \%$ of the alleles in the Iranian selections. In visits by the author to orchards near the Caspian Sea, little phenotypic diversity was seen and nut yields were low, which is consistent with a narrow genetic base. It is unclear if $C$. avellana is native to Iran, and it seems likely that the species was introduced. In all other countries from which seeds were collected, hazelnut bushes could be seen growing in roadsides and hedgerows. Such seedlings were not seen in Iran. In fact, even a large hazelnut planting visited in the Talesh Mountains had been established by planting seedlings.

OTher Selections. Of the selections in the miscellaneous group, 13 originated in northern Italy, three originated in Latvia, and one from Lithuania. The nuts received from Latvia and Lithuania were large and presumably from a collection of cold-hardy cultivars with large nuts. The most common alleles in this miscellaneous group were $S_{9}, S_{5}, S_{6}$, $S_{10}$, and $S_{15}$.

Differences Between CULTIVARS AND SELECTIONS. Differences in allele frequencies (Table 11) between cultivars and selections reflect their geographic origin. The most common Salleles in cultivars and selections in each group are presented in Table 12. Most of the cultivars were from western Europe, whereas most of the selections belonged to the Black Sea group and originated in the eastern part of the distribution of $C$. avellana. $S_{4}$ was very common in selections from Turkey, Georgia, Azerbaijan, Armenia, and Russia. $S_{8}$ and $S_{12}$ were common in Turkish selections. These three alleles were much more common in the selections than in the cultivars. On the other hand, some alleles were more common in the cultivars than in the selections. $S_{1}$ and $S_{2}$ were common in the SpanishItalian cultivars and $S_{3}$ and $S_{11}$ were common in the English cultivars. $S_{5}$ was common in the Central European cultivars, whereas $S_{6}$ was present in the Spanish-Italian and other cultivars. All six of these alleles were present in the selections but at lower frequency than in the cultivars.

The SPREAD OF HAZELNUT AND ORIGIN OF Cultivars. Corylus avellana is found throughout Europe, the Caucasus, and Asia Minor where it is generally found as an understory shrub in mixed deciduous forests. Palme and Vendramin (2002) used four polymorphic chloroplast microsatellite markers to investigate diversity in 248 individuals representing 26 natural 
Table 10. Frequency of S-alleles in hazelnut selections originating in eight seed lots collected in Russia.

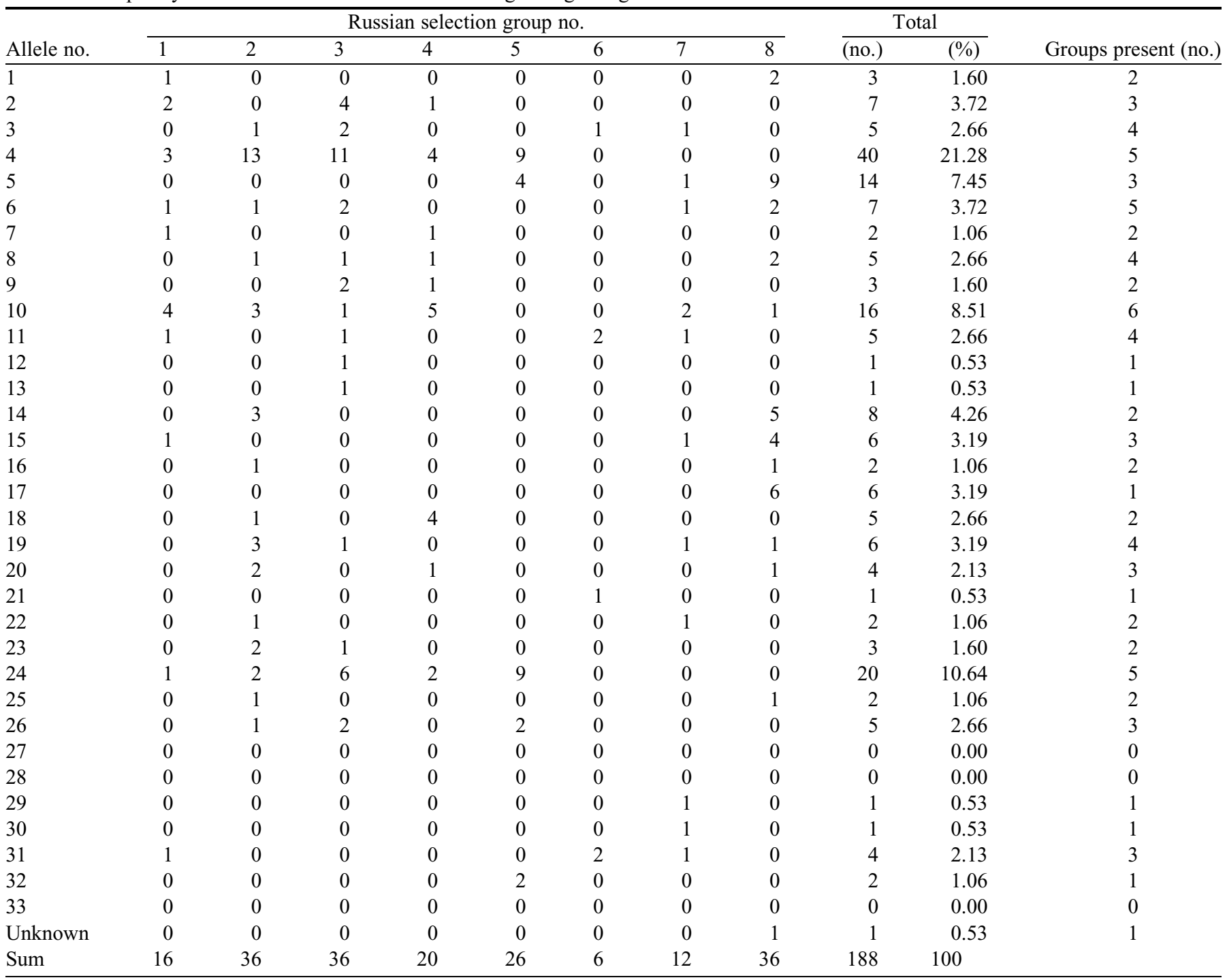

populations across Europe but did not include samples from Turkey, the Caucasus, or Iran. Boccacci and Botta (2009) used the same markers to investigate diversity in 75 cultivars, including a few from Turkey and Iran but none from the Caucasus republics or southern Russia. Both studies give insight into the spread of the hazelnut and its domestication. The chloroplast is generally inherited maternally in angiosperms and thus only dispersed by seeds. The present-day distribution of $C$. avellana was established $\approx 7,000 \mathrm{BP}$ as a result of postglacial recolonization that had started $\approx 11,000$ years earlier (Huntley and Birks, 1983). Between 10,000 and 9,000 BP, there was a sharp increase in the amount of Corylus L. pollen found across Europe (Huntley and Birks, 1983). Nut dispersal during the postglacial recolonization was caused by small mammals, birds, and human migration. Archaeologists have repeatedly found nuts, kernels, and shell remains from many archaeological sites all over Europe. Hazelnuts are easy to store and transport, and kernels have a high energy value; thus, it is likely that Mesolithic tribes aided the spread of hazelnut and undoubtedly selected for productivity.
Palme and Vendramin (2002) found a clear geographical structure of chloroplast haplotypes that divides Europe into two parts. Chlorotype A, which represented $76 \%$ of the sampled wild individuals, and chlorotype B, which represented $4 \%$, were well distributed across western and northern Europe. Chlorotypes C, D, E, and F were restricted to southern and central Italy, Croatia, Romania, and Greece. These results indicate that recolonization of most of Europe was from one or more refugia in southwestern France by the Bay of Biscay. Expansion in Italy and the Balkans, where almost all chlorotype diversity was observed, was local.

Where and when the domestication of $C$. avellana was started is not yet clear, although it was cultivated by the Romans, especially in the southern Italian region of Campania. According to Trotter (1921), cultivars were selected from local wild populations. Many cultivars have unclear origins. Chloroplast marker data for 75 hazelnut cultivars (Boccacci and Botta, 2009) suggested considerable exchange of germplasm between Italy and Spain, probably by the Romans, and thus a common genetic base of cultivars in the two countries. Boccacci and Botta (2009) propose separate domestication of hazelnut in 
Table 11. Differences in the frequency of S-alleles in hazelnut cultivars and selections. ${ }^{\mathrm{z}}$

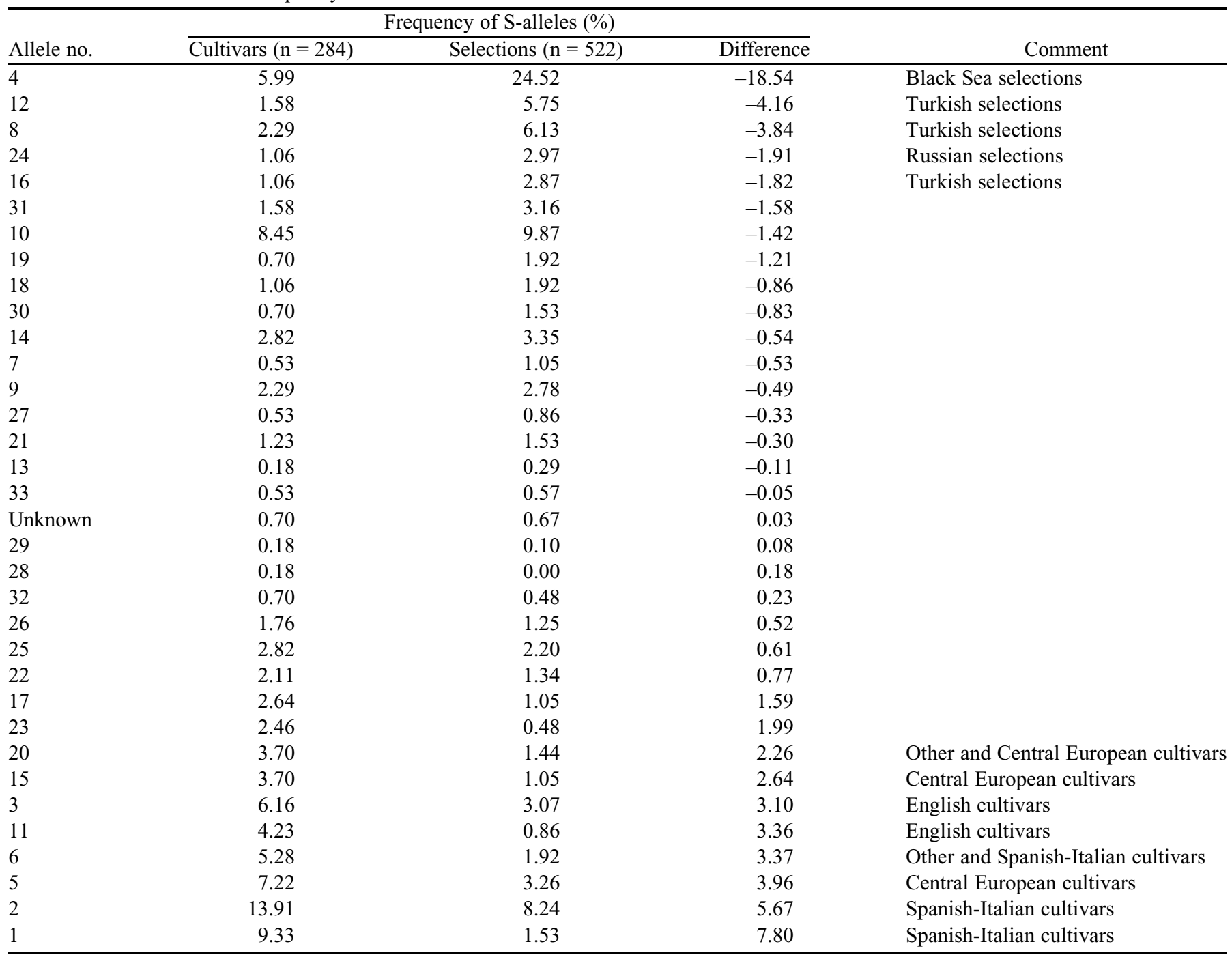

${ }^{\mathrm{z}}$ Alleles are ranked from largest negative to largest positive difference.

three areas: the Mediterranean (Spain and Italy), Turkey, and Iran. Boccacci and Botta (2009) detected little gene flow from east to west. The presence of chlorotype $\mathrm{A}$ in all cultivar groups may be the result of spread of hazelnut throughout the empire by the Romans. Further studies of chlorotypes of germplasm from the Caucasus republics (Georgia, Armenia, and Azerbaijan) and southern Russia will be enlightening.

According to Erfatpour et al. (2011), hazelnut is native to the Talesh Mountains in northwestern Iran (Tandehbin and Makesh regions of Guilan Province). The nuclear microsatellite data of Erfatpour et al. (2011) and Ghanbari et al. (2005) show considerable variation among Iranian hazelnut cultivars in contrast to our observations during orchard visits. The people of Azerbaijan are Turkic. Treaties signed by Russia and Persia in 1813 and 1828 divided Azerbaijan. Today, the northern third is the republic of Azerbaijan and the southern two-thirds remain part of Iran. Some exchange of plant materials among farmers and gardeners would be expected. The ancient Silk Road passed through Iran, and it seems likely that hazelnut were disseminated along the route.

Although the origins of many hazelnut cultivars are unknown, humans undoubtedly played a role in their selection and spread through clonal or seed propagation. Like with other fruit and nut crops, superior cultivars are propagated and sold by nurseries, farmers, and gardeners often sharing scions, rooted suckers, and seeds. Goeschke (1887) described many old cultivars. In England, the major cultivar is DuChilly (syn. 'Kentish Cob'). Richard Webb of Reading is credited as the source of 'Cosford', 'Daviana', 'Garibaldi', 'Empress Eugenia', and 'Princess Royal'. In Germany, at least five people are credited with developing locally adapted types with large nuts. S.D.L. Henne of Gunsleben is the originator of 'Gunslebener Zeller'. Jacob Mackoy et Cie in Luttich is the originator of 'Berger's Zeller'. C.R. Peicker of Hertwigswalde is the originator of 'Louisen's Zeller' and 'Neue Riesen'. C.G. Buttner of Halle is the originator of 'Hall's Giant' (syn. 'Halle'sche Riesennuss') and 'Volle Zeller'. Justizrat Burchardt of Landsberg is credited as the originator of no less than 12 cultivars, including 'Buttner's Zeller', 'Gubener Zeller', 'Gustav's Zeller', 'Riekchen's Zeller', and 'Truchsess Zeller'. Some of these German cultivars were the parents of others. As noted earlier, cultivars selected by growers in the Pacific Northwestern United States and placed in the English group have been identified as hybrids between 
Table 12. Most common S-alleles in hazelnut cultivars and selections by group.

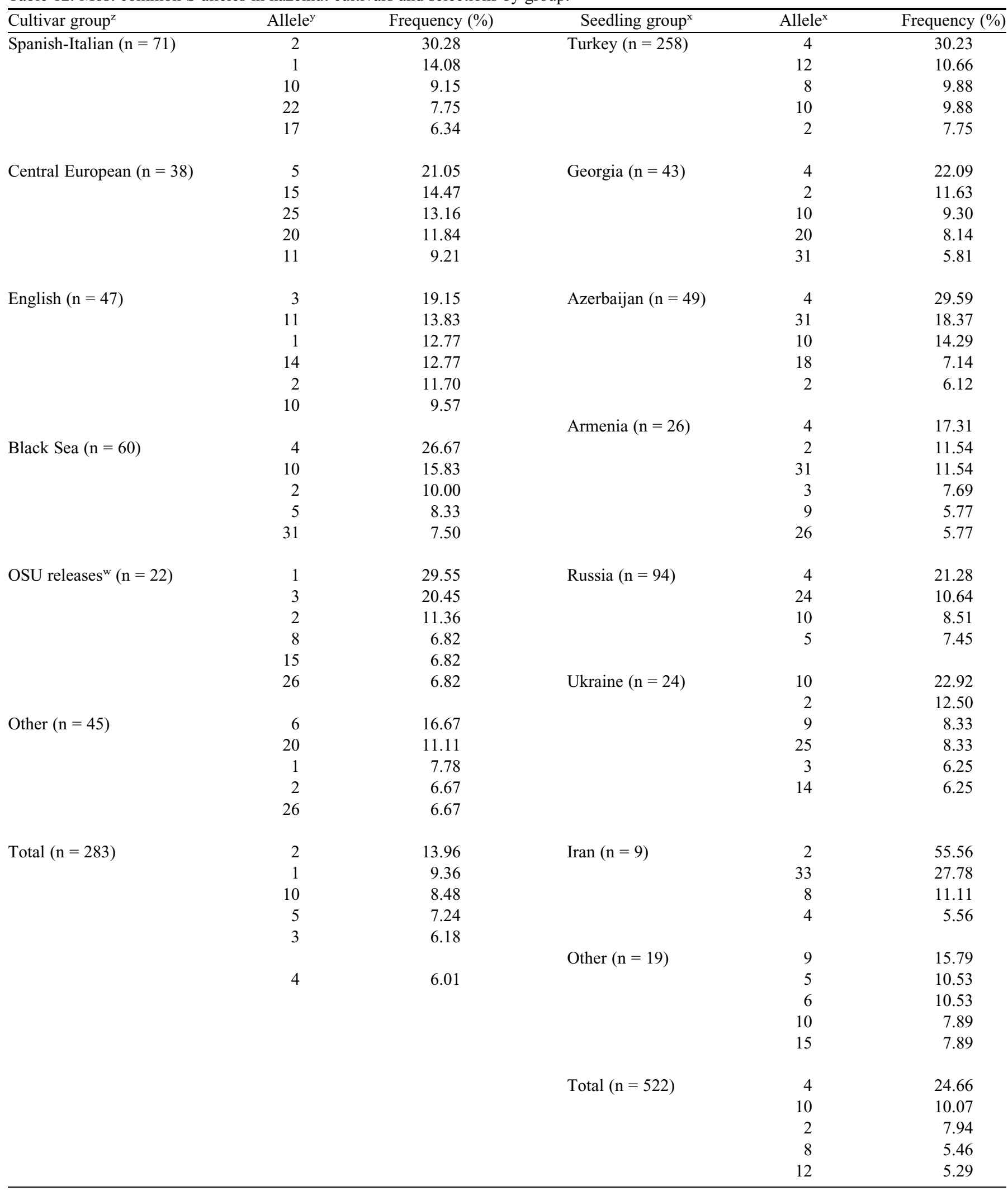

${ }^{\mathrm{z}}$ Number of cultivars or seedlings in each group (n) is shown.

${ }^{\mathrm{y}}$ Alleles in cultivars with frequencies greater than $6 \%$.

${ }^{\mathrm{x}}$ Alleles in seedlings with frequencies greater than $5 \%$.

${ }^{\mathrm{w}} \mathrm{OSU}=$ Oregon State University. 
'Barcelona' and three other cultivars: Daviana, Cosford, and DuChilly.

\section{Conclusions}

Hazelnut cultivars and selections are self-incompatible. Fluorescence microscopy is routinely used to determine if a pollination is compatible or incompatible, and use of an array of known testers allows identification of the alleles of cultivars and selections. Both alleles are expressed in the stigmas, but often only one is expressed in the pollen because of dominance. This study reports six new S-alleles, an improved tester for $S_{13}$, and the dominance relationships for 105 new pairs of alleles. The S-alleles of 284 cultivars, 13 interspecific hybrids, and 522 selections of diverse origin are summarized and presented. Most of the world's leading cultivars were selected from the local vegetation near where they are now planted on a commercial scale. Tremendous genetic variability is available in cultivated and wild hazelnuts, but genetic improvement efforts have only recently led to improved cultivars. Based on SSR markers and geographic origin, most hazelnut cultivars have been assigned to one of the four main groups (Spanish-Italian, English, Central European, or Black Sea), yet many accessions lie outside these main clusters. Differences in S-allele frequency related to geographic origin were seen in the cultivars and selections. The S-alleles identified in hazelnut cultivars and selections is information that should be useful to breeders in the planning of crosses, to germplasm curators, and to growers and nurseries as they choose cultivars and pollenizers when designing orchards.

\section{Literature Cited}

Boccacci, P., A. Akkak, and R. Botta. 2006. DNA typing and genetic relations among european hazelnut (Corylus avellana L.) cultivars using microsatellite markers. Genome 49:598-611.

Boccacci, P. and R. Botta. 2009. Investigating the origin of hazelnut (Corylus avellana L.) cultivars using chloroplast microsatellites. Genet. Resources Crop Evol. 56:851-859.

Boccacci, P., R. Botta, and M. Rovira. 2008. Genetic diversity of hazelnut (Corylus avellana L.) germplasm in northeastern Spain. HortScience 43:667-672.

Erdoğan, V., S.A. Mehlenbacher, A.I. Köksal, and H. Kurt. 2005. Incompatibility alleles expressed in pollen of Turkish hazelnut cultivars. Turk. J. Biol. 29:111-116.

Erfatpour, M., Y. Hamidogli, B. Kaviani, R. Fatahi, M. Falahati, D. Javadi, and D. Hashemabadi. 2011. Assessment of genetic diversity among some Iranian hazelnut genotypes using SSR markers. Austral. J. Crop Sci. 5:1286-1291.

Food and Agriculture Organization of the United Nations. 2011. Food and agricultural commodities production. 28 Dec. 2013. <http:// faostat.fao.org/site/339/default.aspx>.
Germain, E. 1994. The reproduction of hazelnut (Corylus avellana L.): A review. Acta Hort. 351:195-209.

Ghanbari, A., A. Akkak, P. Boccacci, A. Talaie, A. Vezbaie, and R. Botta. 2005. Characterization of hazelnut (Corylus avellana L.) cultivars using microsatellite markers. Acta Hort. 686:111-115.

Goeschke, F. 1887. Die Haselnuss, ihre Arten und ihre Kultur. Paul Parey, Berlin, Germany.

Gökirmak, T., S.A. Mehlenbacher, and N.V. Bassil. 2009. Characterization of european hazelnut (Corylus avellana) cultivars using SSR markers. Genet. Resources Crop Evol. 56:147-172.

Gürcan, K., S.A. Mehlenbacher, and V. Erdoğan. 2010. Genetic diversity in hazelnut cultivars from Black Sea countries assessed using SSR markers. Plant Breed. 129:422-434.

Hampson, C., A.N. Azarenko, and A. Soeldner. 1993. Pollen-stigma interactions following compatible and incompatible pollinations in hazelnut. J. Amer. Soc. Hort. Sci. 118:814-819.

Huntley, B. and H.J.B. Birks. 1983. An atlas of past and present pollen maps for Europe: 0-13,000 years ago. Cambridge University Press, Cambridge, UK.

Martins, S., M. Rovira, A.P. Silva, and V. Carnide. 2012. Incompatibility alleles in Portuguese hazelnut landraces. ISRN Agron. doi: 10.5402/2012/154723.

Mehlenbacher, S.A. 1997a. Testing compatibility of hazelnut crosses using fluorescence microscopy. Acta Hort. 445:167-171.

Mehlenbacher, S.A. 1997b. Revised dominance hierarchy for S-alleles in Corylus avellana L. Theor. Appl. Genet. 94:360-366.

Mehlenbacher, S.A. 2013. Incompatibility alleles of hazelnut cultivars. Acta Hort. (in press).

Mehlenbacher, S.A., R.N. Brown, E.R. Nouhra, T. Gökirmak, N.V. Bassil, and T.L. Kubisiak. 2006. A genetic linkage map for hazelnut (Corylus avellana L.) based on RAPD and SSR markers. Genome 49:122-133.

Mehlenbacher, S.A. and D.C. Smith. 1991. Partial self-compatibility in 'Tombul' and 'Montebello' hazelnut. Euphytica 56:231-236.

Mehlenbacher, S.A. and D.C. Smith. 2006. Self-compatible seedlings of the cutleaf hazelnut. HortScience 41:482-483.

Mehlenbacher, S.A. and M.M. Thompson. 1988. Dominance relationships among S-alleles in Corylus avellana L. Theor. Appl. Genet. 76:669-672.

Palme, A.E. and G.G. Vendramin. 2002. Chloroplast DNA variation, postglacial recolonization and hybridization in hazel, Corylus avellana. Mol. Ecol. 11:1769-1779.

Smith, D.C. and S.A. Mehlenbacher. 1994. Use of Tyvek housewrap for pollination bags in breeding hazelnut (Corylus avellana L.). HortScience 29:918.

Thompson, M.M. 1979a. Genetics of incompatibility in Corylus avellana L. Theor. Appl. Genet. 54:113-116.

Thompson, M.M. 1979b. Incompatibility alleles in Corylus avellana cultivars. Theor. Appl. Genet. 55:29-33.

Thompson, M.M. 1985. Linkage of the incompatibility locus and red pigmentation genes in hazelnut. J. Hered. 76:119-122.

Trotter, A. 1921. Contributo alla storia colturale del nocciuolo nella Campania. Ristampa di una comunicazione fatta al Congresso di Arboricoltura Meridionale, Napoli, Italy, 16-20 Sept. 1921. p. 3-19. 